\title{
Surface-sensible and latent heat fluxes over the Tibetan Plateau from ground measurements, reanalysis, and satellite data
}

\author{
Q. Shi ${ }^{1}$ and S. Liang ${ }^{1,2,3}$ \\ ${ }^{1}$ Department of Geographical Sciences, University of Maryland, College Park, Maryland, USA \\ ${ }^{2}$ State Key Laboratory of Remote Sensing Science, Jointly Sponsored by Beijing Normal University and the Institute of \\ Remote Sensing Applications of Chinese Academy of Sciences, Beijing, China \\ ${ }^{3}$ State Key Laboratory of Remote Sensing Science and College of Global Change and Earth System Science, Beijing Normal \\ University, Beijing, China \\ Correspondence to: Q. Shi (qshi@umd.edu)
}

Received: 3 September 2013 - Published in Atmos. Chem. Phys. Discuss.: 21 November 2013

Revised: 4 April 2014 - Accepted: 19 April 2014 - Published: 6 June 2014

\begin{abstract}
Estimations from meteorological stations over the Tibetan Plateau (TP) indicate that since the 1980s the surface-sensible heat flux has been decreasing continuously, and modeling studies suggest that such changes are likely linked to the weakening of the East Asian Monsoon through exciting Rossby wave trains. However, the spatial and temporal variations in the surface-sensible and latent heat fluxes over the entire TP remain unknown. This study aims to characterize the spatial and seasonal variability of the surfacesensible and latent heat fluxes at $0.5^{\circ}$ over the TP from 1984 to 2007 by synthesizing multiple data sources including ground measurements, reanalysis products, and remotesensing products. The root mean square errors (RMSEs) from cross validation are $14.3 \mathrm{Wm}^{-2}$ and $10.3 \mathrm{Wm}^{-2}$ for the monthly fused sensible and latent heat fluxes, respectively. The fused sensible and latent heat-flux anomalies are consistent with those estimated from meteorological stations, and the uncertainties of the fused data are also discussed. The associations among the fused sensible and latent heat fluxes and the related surface anomalies such as mean temperature, temperature range, snow cover, and normalized difference vegetation index (NDVI) in addition to atmospheric anomalies such as cloud cover and water vapor show seasonal dependence, suggest that the land-biosphere-atmosphere interactions over the TP could display nonuniform feedbacks to the climate changes. It would be interesting to disentangle the drivers and responses of the surface-sensible and latent heat-flux anomalies over the TP in future research from evidences of modeling results.
\end{abstract}

\section{Introduction}

The land surface energy balance (SEB) is a critical physical characteristic of the land surface processes. It states the ability of the land surface to partition the net radiation (NR) into latent heat flux (LE), sensible heat flux $(H)$, and ground heat flux $(G)$ (Eq. 1), which governs the hydrological, biogeochemical, and ecological processes at the Earth's surface (Liang et al., 2010):

$\mathrm{NR}=\mathrm{LE}+H+G$.

In contrast to the global land SEB that has been accessed by using surface observations, remote-sensing, and reanalysis data sets, less attention has been paid to analyzing the spatiotemporal characteristics of the land SEB at the regional scale due to the limit number of ground observation sites and the lack of comprehensive validation (Kiehl and Trenberth, 1997; Trenberth et al., 2009; Jung et al., 2011; Stephens et al., 2012; Stevens and Schwartz, 2012; Wild, 2012). Although limited long-term ground observations measure the SEB, the decadal changes of evapotranspiration have been quantified empirically by using ground measurements and remote-sensing observations (Wang and Liang, 2008; Jung et al., 2010; Yao et al., 2012). However, it is important to conduct comprehensive validation and comparison before applying global data sets at the regional scale, because the reliability of such data sets is largely dependent on the characteristics of inputs such as the homogeneity of satellite products and the distribution of stations (Mueller et al., 2013). 
The SEB over the Tibetan Plateau (TP) is of great research interest because of its physical links to the East Asian monsoon, which sustains approximately $25 \%$ of the world's population (Wang and Liang, 2008; Immerzeel et al., 2010). Numerical experiments and geologic observations have supported the theory such that the formation of the Asian monsoon is related to the uplift of the TP (Kutzbach et al., 1993; An et al., 2001). In addition to the mechanical forcing of the TP through partitioning of the jet stream (Manabe and Terpstra, 1974), physical processes by which the thermal forcing of the TP is linked to the onset and strength of the Asian monsoon have been inferred from the shift of the jet stream, the formation of the south Asian high, the diurnal variation of meteorological observations of the TP, and numerical experiments (Ye and Gao, 1979; Yanai and Li, 1994; Ye and Wu, 1998; G. Wu et al., 2012). The concept of "sensibleheat driven air pump" over the TP has been proposed in research of the elevated heating effect over the TP by using the global circulation model (GCM) (G. Wu et al., 2007). This concept suggests that the surface heating (cooling) in summer (winter) causes air columns to converge (diverge) and to ascend (descend), regulating both local and Northern Hemisphere circulation. Furthermore, such processes create the south Asian high in the upper atmosphere in summer and the increasingly high pressure over continental areas in winter, likely contributing to the pattern of droughts in the north and floods in the south in China in addition to the country's cold continental climate, respectively (Duan et al., 2013).

The SEB over the TP is essential for the study of landbiosphere-atmosphere interactions, analysis of the changes in terrestrial ecosystems and hydrological systems, and assessment of the impacts of and feedbacks to the climate changes. Previous research has investigated the diurnal, seasonal and annual variation of the SEB at stations over various land cover types in the TP, including grassland (Y. Ma et al., 2003; Tanaka et al., 2003; Liu et al., 2009; Bian et al., 2012), meadow (Gu et al., 2005; Yao et al., 2008, 2011), and glacial and alpine areas (Zou et al., 2009; Yang et al., 2011c; Chen et al., 2012; Zhang et al., 2013). Advanced methods have been developed to retrieve SEB from improved parameterization of routine meteorological observations (Yang et al., 2002, 2003, 2008; Chen et al., 2010, 2013b; Guo et al., 2011b; Lee et al., 2012) satellite observations (Y. Ma et al., 2006, 2012; W. Ma et al., 2009, 2011; Jiménez et al., 2009; Zhang et al., 2010), and the integration of both data sources (Wang and Liang, 2008; Jung et al., 2009; Yao et al., 2012). The uncertainties of those approaches in characterizing the SEB over the TP, however, remain large, resulting in misrepresentation and inconsistency of the inferred decadal changes of the sensible heat flux from reanalysis or the conventional bulk aerodynamic method (Yang et al., 2011b; Zhu et al., 2012). Specifically, observation-based results are inadequate for determining the regional pattern of the SEB over the entire TP due to the unbalanced distribution of meteorological stations and the sparse temporal coverage of the remote-

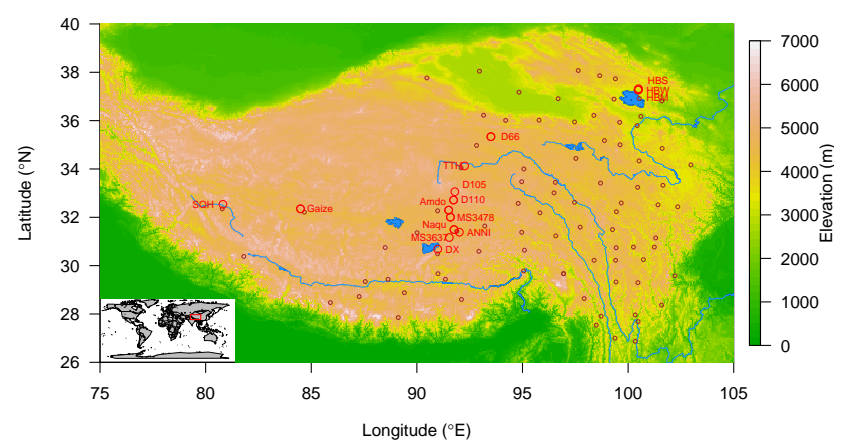

Figure 1. Study area with major lakes, rivers, six regions, validation sites (red large circle), and CMA stations for comparison (red small circle).

sensing products under the requirement of clear-sky conditions (Y. Ma et al., 2006, 2011), whereas the reliability of modeling results is largely limited not only by the propagation of input error through the model retrieval (Wang and Dickinson, 2012), but also by the uncertainty of parameterization under complex terrain and highly heterogeneous areas (Chen et al., 2013a). Instead, GCMs have been applied extensively to access the effects of warming (Wang et al., 2008, 2011), snow forcing (Qian et al., 2011; Turner and Slingo, 2011), and weakened sensible heat flux (Liu et al., 2012; G. Wu et al., 2012; Duan et al., 2013) over the TP on the precipitation changes in East Asia. Nevertheless, gaps remain in quantification of the decadal changes of the SEB over the $\mathrm{TP}$ at the regional scale in comparison with changes derived from ground observations and in assessment of the relationship between the changes of the SEB and the observed surface and atmospheric conditions.

The objective of this study is to analyze the spatiotemporal characteristics of the surface-sensible and latent heat fluxes over the TP by integrating ground observations, remotesensing, and reanalysis data sets over the recent two decades. The following sections introduce various data sources and methodologies including preprocessing, data fusion, and spatiotemporal characterization; describe the validation results; discuss the uncertainties of the fused data; investigate the spatial and seasonal variability; and conclude with major findings and implications derived from the results.

\section{Data sets}

The TP includes areas with elevations higher than $3000 \mathrm{~m}$ within approximately $30^{\circ}$ longitude $\left(75-105^{\circ} \mathrm{E}\right)$ and $14^{\circ}$ latitude $\left(26-40^{\circ} \mathrm{N}\right)$ (Fig. 1). To integrate observational and modeling results of the SEB over the $\mathrm{TP}$, the following three sources data were included: (1) ground-measurement data from AsiaFlux, ChinaFLUX, GAME/Tibet, and CAMP/Tibet; (2) state-of-the-art reanalysis products from the Climate Forecast System Reanalysis 
(CFSR), the Modern-Era Retrospective analysis for Research and Applications (MERRA), the ERA-Interim reanalysis, and the Japanese 25 year Reanalysis (JRA-25); and (3) two remote-sensing-based products: a global evapotranspiration model developed by Zhang et al. (2010), hereafter referred to as Zhang10, and a global evapotranspiration model based on the Global Land Evaporation: the Amsterdam Methodology (GLEAM) (Miralles et al., 2014), hereafter referred to as GLEAM-LE (Table 1).

\subsection{Ground-measured data sets}

Surface energy fluxes based on ground measurement were extracted from three sources: the Coordinated Energy and Water Cycle Observation Project (CEOP) (Koike, 2004), the Asian Automatic Weather Station Network (ANN) (Sugita et al., 2005), and FLUXNET (Baldocchi et al., 2001). Between 1997 and 2007, ground SEB measurements from 13 stations were selected from the AsiaFlux sites (Kim et al., 2009), the ChinaFLUX sites (Yu et al., 2006), the Global Energy and Water Cycle Experiment (GEWEX) Asian Monsoon Experiment on the TP (GAME/Tibet; http://monsoon.t.u-tokyo. ac.jp/tibet), and the CEOP Asia-Australia Monsoon Project on the TP (CAMP/Tibet; http://data.eol.ucar.edu/codiac/dss/ $\mathrm{id}=76.127$ ). Those stations were not used in the development of remote-sensing and reanalysis products. The critical information used in station selection for extracting highquality SEB measurements includes location, measured variables, measured height, instruments, data period, and number of days (Table 2). The ground heat flux is recorded by a soil heat-flux plate at a depth below the surface ranging from $0.01 \mathrm{~m}$ to $0.1 \mathrm{~m}$ with expected accuracy by $\pm 5 \%$ of reading for Campbell HFT-3 and EKO MF-81, and -15 to $+5 \%$ of the $12 \mathrm{~h}$ total for Hukseflux HFP01. The eddycovariance method measures sensible and latent heat fluxes from high-frequency flux covariance (by $10 \mathrm{~Hz}$ ) of the wind vector from a three-dimensional sonic anemometer (Campbell CSAT-3, GILL SAT-R3A, and Kaijo DA-600) and the humidity fluctuation from an open-path infrared gas analyzer (LI-COR LI-7500 and Kaijo AH-300), a krypton hygrometer (Campbell KH20), or a thermohygrometer (Vaisala $50 Y$ Bandpass TRH). Based on the manufactory specifications, the estimated accuracy of GILL SAT-R3A is $<1 \%$ root mean square (RMS) of the reading; LI-COR LI-7500, $\pm 2 \%$ of the reading; Campbell $\mathrm{KH} 20, \pm 5 \%$ of the reading; and Campbell CSAT-3, $\pm 6 \%$ of the horizontal as gain error and $\pm 8.0 \mathrm{~cm} \mathrm{~s}^{-1}\left( \pm 4.0 \mathrm{~cm} \mathrm{~s}^{-1}\right)$ of horizontal (vertical) offset error. The typical estimated error of the eddy-covariance measurements is $5-20 \%$ including $20-50 \mathrm{Wm}^{-2}$ and $10-$ $30 \mathrm{Wm}^{-2}$ for latent heat and sensible heat fluxes, respectively (Foken, 2008). Since the enclosure ratio of the eddycovariance measurements is approximately $20 \%$ (Foken et al., 2006), later a correction is applied to the eddy-covariance measurements in this study (Sect. 3.1).
As regional branches of FLUXNET, AsiaFlux and ChinaFLUX measure carbon cycle, hydrological cycle, and energy exchange to study the interaction between the terrestrial ecosystem and the atmosphere. The AsiaFlux site, an alpine meadow grassland in Haibei (HBM), China, offers 15 min averaged SEB measurements, which removes unreliable data by using absolute-threshold quality control (Vickers and Mahrt, 1997). The longest measurements of the SEB over the TP are acquired from two ChinaFLUX sites where SEB is averaged at $30 \mathrm{~min}$ intervals after applying the correction for the density effect to latent heat flux from 2003 to 2007 at the Damxung site (DX) and from November 2002 to 2007 at the Haibei shrubland site (HBS) (Webb et al., 1980).

GAME/Tibet and CAMP/Tibet are organized by the international monsoon experiments. At $30 \mathrm{~min}$, SEB averages were extracted from GAME/Tibet during the intensive observation period (IOP) in 1998, which included portable automated mesonets (PAM) at MS3478, planetary boundary layer (PBL) tower measurements of radiation fluxes and turbulent flux measurements at Amdo and BJ stations, respectively. CAMP/Tibet radiation and flux data sets were collected during the Enhanced Observing Period 3 (EOP-3) and Enhanced Observing Period 4 (EOP-4) of CEOP, covering the period from October 2002 to December 2004. Six stations including Amdo, ANNI, D105, MS3478, BJ, and Gaize measured soil heat flux from $0.2 \mathrm{~Hz}$ samples and averages at $10 \mathrm{~min}$ intervals. Comprehensive measurements have been taken at the BJ site, including $3 \mathrm{~m}$ latent and sensible heat fluxes averaged over $30 \mathrm{~min}$ intervals. Heat fluxes from CAMP/Tibet were visually examined for low and high extreme or constant values by using the CAMP Quality Control Web Interface; data with quality flags of good or interpolated were used in this study. Because most sites share the same locations with GAME/Tibet but use different instruments, observations from multiple data sets of the same sites were combined before analysis.

Two data sets based on meteorological station data over the TP reported by (Yang et al., 2009) and (Yang et al., 2011a), hereafter referred to as Yang09 and Yang11, respectively, were chosen for comparison purposes. Yang09 estimates the daily sensible heat flux of 85 China Meteorological Administration (CMA) stations over the TP by using a micro-meteorological method, a physical scheme similar to the eddy-covariance method but which includes statistical downscaled wind speed and ground-air temperature from the CMA stations. The advantage the Yang09 scheme has over conventional methods is that it produces a realistic estimation of the sensible heat flux by accounting for the diurnal variation of the heat transfer process (Yang et al., 2011b). Based on the $250 \mathrm{~m}$ normalized difference vegetation index (NDVI) from the global Moderate Resolution Imaging Spectroradiometer (MODIS) vegetation indices product (MOD13Q1), data of 59 CMA stations with elevations $>3000 \mathrm{~m}$ under the NDVI $<0.2$ and snow-free conditions were selected by considering the quality flag of MOD13Q1 because of the 
Table 1. Summary of data sources $(*$ for comparison).

\begin{tabular}{|c|c|c|c|c|}
\hline Name & $\begin{array}{l}\text { Organization/ } \\
\text { institution }\end{array}$ & $\begin{array}{l}\text { Spatial } \\
\text { resolution/ } \\
\text { stations }\end{array}$ & $\begin{array}{l}\text { Temporal } \\
\text { resolution }\end{array}$ & $\begin{array}{l}\text { Temporal } \\
\text { coverage }\end{array}$ \\
\hline \multicolumn{5}{|c|}{ Reanalysis data sets } \\
\hline CFSR & NCEP & $\mathrm{T} 382(38 \mathrm{~km})$ & hourly & Jan 1979-Dec 2009 \\
\hline MERRA & NASA & $0.50^{\circ} \times 0.67^{\circ}$ & hourly & Jan 1979-Apr 2013 \\
\hline ERA-Interim & ECMWF & $\mathrm{T} 255(80 \mathrm{~km})$ & 3 hourly & Jan 1979-Mar 2013 \\
\hline JRA-25 & JMA/CRIEPI & $\mathrm{T} 106(110 \mathrm{~km})$ & 3 hourly & Jan 1979-Dec 2011 \\
\hline MERRALAND* & NASA & $0.50^{\circ} \times 0.67^{\circ}$ & hourly & Jan 1979-Apr 2013 \\
\hline NRA-1* & NCEP/NCAR & T62 (200 km) & 6 hourly & Jan 1948-Jul 2012 \\
\hline NRA-2* & NCEP/NCAR & T62 (200 km) & 6 hourly & Jan 1979-Dec 2011 \\
\hline GLADS-1_NOAH* & NCAR & $1.00^{\circ}$ & 3 hourly & Jan 1979-May 2012 \\
\hline GLADS-2_NOAH* & NCAR & $1.00^{\circ}$ & 3 hourly & Jan 1948-Dec 2008 \\
\hline GLADS-1_CLM* & NCAR & $1.00^{\circ}$ & 3 hourly & Jan 1979-May 2012 \\
\hline GLADS-1_MOS* & NASA/GSFC & $1.00^{\circ}$ & 3 hourly & Jan 1979-May 2012 \\
\hline \multicolumn{5}{|c|}{ Remote-sensing data sets } \\
\hline Zhang10 & NASA & $8 \mathrm{~km}$ & monthly & Jan 1983-Dec 2006 \\
\hline GLEAM-LE & UB & $0.25^{\circ}$ & daily & Jan 1984-Dec 2007 \\
\hline PU-ET* & PU & $0.50^{\circ}$ & 3 hourly & Jan 1984-Dec 2007 \\
\hline \multicolumn{5}{|c|}{ Ground-measured data sets } \\
\hline AsiaFLUX & FLUXNET & 1 stations & $15 \mathrm{~min}$ & Jul 2002-Dec 2004 \\
\hline ChinaFLUX & FLUXNET & 3 station & $30 \mathrm{~min}$ & Nov 2002-Dec 2007 \\
\hline GAME/Tibet & AAN & 10 stations & $30 \mathrm{~min}$ & Dec 1994-Apr 2005 \\
\hline CAMP/Tibet & CEOP & 9 stations & 10 min, hourly & Oct 2002-Dec 2004 \\
\hline Yang09, Yang11* & ITPR CAS & 85 stations & daily & Jan 1984-Dec 2006 \\
\hline
\end{tabular}

suitability of the Yang09 scheme for bare soil or spares vegetation land cover. Yang11 provides the simulation results of the SEB of the CMA stations over the TP by using the SiB2 adjusted land surface model (Sellers et al., 1996) according to the TP surface characteristics reported from previous experiments (Yang et al., 2008). In recent studies, the climatology and trend of sensible heat flux over the TP extracted from Yang11 have been compared to that from reanalysis data sets, suggesting a general weakened trend of the sensible heat source over the TP in recent decades, with large uncertainties among different data sets (Liu et al., 2012; Zhu et al., 2012).

\subsection{Remote-sensing data sets}

Remote-sensing-based estimations of evapotranspiration have been developed to access decadal changes of evapotranspiration over the pan-Arctic basin and Alaska (Zhang et al., 2009), which were then applied to the global land surface (Zhang et al., 2010). Zhang10 estimates evapotranspiration over vegetated areas by a modified Penman-Monteith approach with a biome-specific canopy conductance model parameterized from 34 FLUXNET sites. The major inputs are NDVI from the Advanced Very High Resolution Radiometer (AVHRR) provided by NASA Global Inventory Model- ing and Mapping Studies (GIMMS) (Tucker et al., 2005), air temperature and water vapor pressure from the National Center of Environmental Prediction (NCEP)/National Center for Atmospheric Research (NCAR) (NCEP/NCAR) reanalysis version 1 (NRA-1) (Kalnay et al., 1996), and shortwave radiation from GEWEX Surface Radiation Budget (GEWEX SRB 3.0) (Pinker and Ewing, 1985; Pinker and Laszlo, 1992). The independent validation over 48 FLUXNET sites including HBM satisfied accuracy at $R^{2}=0.80-0.84$. A recent evaluation of Zhang10 suggests that it outperforms other reanalysis and remote-sensing data sets over the upper Yellow River and Yangtze River basins in the TP (Xue et al., 2013).

Recently, a global land evaportranspiration data set has been developed by using GLEAM (Miralles et al., 2011a, b, 2014). GLEAM applied a Priestley-Taylor approach to estimate the potential evaporation from observed surface net radiation and air temperature. The actual evaportranspiration is estimated from potential evaporation multiplied by the evaporative stress factor, which is derived from the observed vegetation optical depths (to approximate vegetation water content) and the estimated root zone soil moisture. The difference between the GLEAM evaportranspiration and the FLUXNET observations is within $\pm 20 \%$ at most sites. 
Table 2. Information of the ground observation sites over the TP with measurement of latent heat flux (LE), sensible heat flux $(H)$, and ground heat flux $(G)$.

\begin{tabular}{|c|c|c|c|c|c|c|c|c|}
\hline $\begin{array}{l}\text { Name } \\
\text { Name }\end{array}$ & $\begin{array}{l}\text { Lat } \\
\left({ }^{\circ} \mathrm{N}\right)\end{array}$ & $\begin{array}{l}\text { Long } \\
\left({ }^{\circ} \mathrm{S}\right)\end{array}$ & $\begin{array}{l}\text { EL } \\
(\mathrm{m})\end{array}$ & $\begin{array}{l}\text { Measured } \\
\text { variable }\end{array}$ & Height & Instruments & $\begin{array}{l}\text { Data } \\
\text { period }\end{array}$ & $\begin{array}{r}\text { Date } \\
\text { length }\end{array}$ \\
\hline \multicolumn{9}{|c|}{ AsiaFlux } \\
\hline \multirow[t]{2}{*}{ HBM } & 37.61 & 101.31 & 3250 & LE, $H$ & $2.2 \mathrm{~m}$ & Campbell CSAT-3, LI-COR LI-7500 & Jul 2002-Dec 2004 & 519 \\
\hline & & & & $G$ & $-0.01 \mathrm{~m}$ & Campbell HFT-3 & & 942 \\
\hline \multicolumn{9}{|c|}{ CAMP/Tibet } \\
\hline Amdo & 32.24 & 91.62 & 4695 & $G$ & $-0.10 \mathrm{~m}$ & EKO MF-81 & Oct 2002-Dec 2004 & 520 \\
\hline ANNI & 31.25 & 92.17 & 4480 & $G$ & $-0.10 \mathrm{~m}$ & EKO MF-81 & Oct 2002-Dec 2004 & 328 \\
\hline D105 & 33.06 & 91.94 & 5038 & $G$ & $-0.10 \mathrm{~m}$ & EKO MF-81 & Oct 2002-Dec 2004 & 765 \\
\hline MS3478 & 31.92 & 91.71 & 4619 & $G$ & $-0.10 \mathrm{~m}$ & EKO MF-81 & Oct 2002-Dec 2004 & 820 \\
\hline \multirow[t]{2}{*}{$\mathrm{BJ}$} & 31.37 & 91.90 & 4509 & LE, $H$ & $3.00 \mathrm{~m}$ & Kaijo DA-600, LI-COR LI-7500 & Oct 2002-Dec 2004 & 51 \\
\hline & & & & $G$ & $-0.10 \mathrm{~m}$ & EKO MF-81 & & 654 \\
\hline Gaize & 32.30 & 84.05 & 4416 & $G$ & $-0.03 \mathrm{~m}$ & EKO MF-81 & Oct 2002-Dec 2004 & 698 \\
\hline \multicolumn{9}{|c|}{ ChinaFLUX } \\
\hline \multirow[t]{2}{*}{ DX } & 30.50 & 91.07 & 4751 & LE, $H$ & $2.2 \mathrm{~m}$ & Campbell CSAT-3, LI-COR LI-7500 & Jun 2003-Dec 2007 & 1097 \\
\hline & & & & $G$ & $-0.05 \mathrm{~m}$ & Hukseflux HFP01 & & 1597 \\
\hline \multirow{2}{*}{ HBS } & 37.67 & 101.33 & 3400 & LE, $H$ & $2.2 \mathrm{~m}$ & Campbell CSAT-3, LI-COR LI-7500 & Dec 2002-Dec 2007 & 1107 \\
\hline & & & & $G$ & $-0.05 \mathrm{~m}$ & Hukseflux HFP01 & & 1726 \\
\hline \multicolumn{9}{|c|}{ GAME/Tibet } \\
\hline \multirow[t]{2}{*}{ Amdo } & 32.24 & 91.63 & 4700 & LE, $H$ & $2.85 \mathrm{~m}$ & Kaijo DA-300, Kaijo AH-300 & Jan 1998-May 2003 & 47 \\
\hline & & & & $G$ & $-0.10 \mathrm{~m}$ & EKO MF-81 & & 1612 \\
\hline \multirow[t]{2}{*}{ MS3478 } & 31.93 & 91.72 & 5063 & LE, $H$ & $2.85 \mathrm{~m}$ & GILL SAT-R3A, Vaisala 50Y Bandpass TRH & May 1998-Sep 1998 & 40 \\
\hline & & & & $G$ & $-0.01 \mathrm{~m}$ & Campbell HFT-3 & & 118 \\
\hline Gaize & 32.30 & 84.05 & 4420 & G & $-0.25 \mathrm{~m}$ & EKO MF-81 & May 1998-Sep 1998 & 117 \\
\hline \multirow[t]{2}{*}{ BJ } & 31.37 & 91.90 & 4580 & LE, $H$ & $2.85 \mathrm{~m}$ & Campbell CSAT-3, Campbell KH20 & May 1998-Sep 1998 & 30 \\
\hline & & & & LG & $-0.05 \mathrm{~m}$ & Campbell HFT-3 & & 89 \\
\hline
\end{tabular}

Considering the temporal coverage and the improved accuracy of the daily evaportranspiration, the data set from the third experiment (e3) from the Miralles et al. (2014) is used in this study, which uses net radiation from GEWEX SRB 3.0, air temperature from the International Satellite Cloud Climatology Project (ISCCP) (Rossow et al., 2004) merged with ERA-Interim and the Atmospheric Infrared Sounder (AIRS) (Ferguson et al., 2010), and precipitation from Climate Prediction Center unified gauge-based analysis (Chen et al., 2008) as major inputs.

\subsection{Reanalysis data sets}

The NCEP CFSR is the first global reanalysis product to apply a coupled land-atmosphere-ocean-sea ice system (Saha et al., 2010). The land surface analysis is produced from the Noah land surface model, which is forced by the output from the atmospheric assimilation in addition to observed precipitation and snow depth (Ek et al., 2003). This model outperforms the previous NCEP reanalysis data sets with higher spatial resolution (T382, approximately $0.31^{\circ}$ ) and improved land surface energy and water closures at the monthly scale (Meng et al., 2012). MERRA, a recent reanalysis data set supported by NASA's Global Modeling and As- similation Office (GMAO) covering temporal period since 1979, incorporates a catchment hydrological model (Koster and Suarez, 1996; Koster et al., 2000) and a multi-layer snow model (Stieglitz et al., 2001) that are coupled to the GOES-5 atmospheric GCM. Global assessments suggest an improvement in the hydrological cycles with MERRA (Rienecker et al., 2011). ERA-Interim is the first reanalysis product to apply the four-dimensional variational data assimilation scheme (4D-Var) provided by the European Centre for Medium-Range Weather Forecasts (ECMWF) (Dee et al., 2011), which assimilates $2 \mathrm{~m}$ air temperature and humidity to correct soil moisture and temperature analyses (Douville et al., 2000). The Tiled ECMWF Scheme for Surface Exchanges over Land (TESSEL) (Viterbo and Beljaars, 1995; Viterbo and Betts, 1999) and the snow scheme (Douville et al., 1995) are used in the ERA-Interim for modeling land surface processes. JRA-25 aims to provide high-quality data for the Asian region by applying the Japan Meteorological Agency (JMA) numerical assimilation and forecast system (Onogi et al., 2007). A simple biosphere scheme is used in JRA-25 with observed snow data (Sellers et al., 1986; Sato et al., 1989). A recent comparison has revealed consistency in the interannual variability and a weakened tendency 
of surface wind speed and sensible heat flux over the TP among JRA-25, Yang11, and NRA-1, whereas large interannual variation and inconsistency have been identified for CFSR (Zhu et al., 2012).

\section{Methodology}

\subsection{Preprocessing}

The residue of the SEB at stations over the TP is likely caused by measuring error, sampling mismatch, soil energy storage, advection, and large-scale eddies from heterogeneity ( $\mathrm{Li}$ et al., 2005; Foken et al., 2006; Foken, 2008). Measurements are mounted at different heights with substantially different footprints at each station, which requires stability and surface homogeneity to close the SEB. In addition, systematic and random errors from in situ measurement have been argued as causes for the SEB imbalance through overestimation (underestimation) of latent and sensible heat fluxes (net radiation). Specifically, analysis from previous studies and high-residue error in summer from the current study suggest that the systematic error from the infrared hygrometer is critical to the closure problem, particularly during rainfall days, which is associated with lower latent heat flux from weakened measured fluctuation of specific humidity (Tanaka et al., 2003; Yang et al., 2004). In addition, the freezing and thawing season is related to variation in closure ratio (CR in Eq. 2), which reaches a negative value in the completely frozen stage (Guo et al., 2011a). Although no agreements or protocols has been reached for the causes and corrections of energy balance and imbalance from eddy-covariance measurement over the TP, closure of the SEB on the dailyscale limits the effect of imbalance from diurnal variation, such as that through the freezing and melting processes and the energy storage from photosynthesis of plants, by calculating the daily average (Tanaka et al., 2003; Yang et al., 2004; Yang and Koike, 2008; Guo et al., 2011a). Extensive eddy-covariance measurements in various climatic regions and land cover types over the TP are required in future research to quantify conditions under which the energy budget is unbalanced.

$\mathrm{CR}=\frac{[(\mathrm{NR}-G)-(\mathrm{LE}+H)]}{(\mathrm{NR}-G)}$

Monthly mean SEB components over the TP were extracted from ground measurements, remote-sensing, and reanalysis data sets. Original ground-measured values of surface latent heat flux, sensible heat flux, and ground heat flux were first converted to coordinated universal time (UTC) and were then integrated to daily hourly mean by using quality control flags to exclude poor-quality and missing data and by corresponding thresholds of $-200-400 \mathrm{Wm}^{-2},-200-500 \mathrm{Wm}^{-2}$, and $-200-300 \mathrm{Wm}^{-2}$. Then, daily mean value was calculated from daily hourly mean values with less than half missing.
The surface energy balance was closed by using the observed Bowen ratio on the daily scale (Twine et al., 2000). The monthly mean value of in situ data was calculated from the daily mean covering more than 15 days in a month. Daily averages of the SEB components were also extracted from the original reanalysis data sets, followed by interpolation to $0.5^{\circ}$ resolution by using the nearest grid data from MERRA, Interim, and JRA-25 or the mean grids value covered by the newly projected grid from CFSR. The monthly mean value was calculated from the daily mean. Similar interpolation was applied to Zhang10 monthly data and the monthly average of the GLEAM-LE, which was converted to latent heat flux by multiplying the latent heat of vaporization, $\lambda\left(2.451 \mathrm{MJ} \mathrm{kg}^{-1}\right)$. The sensible heat flux of Zhang 10 and GLEAM-LE is estimated from the difference between the net radiation from GEWEX SRB 3.0 and the latent heat flux, assuming the ground heat flux is relatively small and negligible (Jiménez et al., 2011).

\subsection{The data fusion method}

The multiple linear regression (MLR) method was used to fuse remote-sensing and reanalysis data sets with ground observations. The data fusion approach synthesizes multiple sources of data to improve accuracy, confidence, and consistency of the results, and the MLR has the advantage of being simple and easily interpreted. The MLR model, using $p$ original data sets $\left(X_{i}\right)$ and the truth $(Y)$ from the groundmeasured data, is expressed as

$Y=\beta_{0}+\sum_{i=1}^{p} \beta_{i} \times X_{i}+\varepsilon, \varepsilon \sim N\left(0, \sigma^{2}\right)$,

where $\beta_{i}\left(\beta_{0}\right)$ is the coefficient (intercept) and $\varepsilon$ is the residual assumed to be normally distributed $\left(N\left(0, \sigma^{2}\right)\right)$. The intercept and coefficients are determined to minimize the sum of the square residuals. This study applied MLR to latent and ground heat fluxes. Similar to the significant large interannual variation of the sensible heat flux from CFSR over the TP (Zhu et al., 2012), the latent heat flux from CFSR was excluded in the data fusion of the latent heat flux because it exhibits significant large interannual variation. In addition to the ground observations, MERRA, ERA-Interim, JRA-25, Zhang10, and GLEAM-LE were the input data sets to derive Eq. (3) for the data fusion of the latent heat flux. This method was also applied to fuse the latent heat flux with those inputs except Zhang 10 in the case of missing data from Zhang10. For the ground heat flux, four reanalysis data sets (i.e., CFSR, MERRA, ERA-Interim, JRA-25) and the ground observations were the inputs for the calibration of the Eq. (3). A monthly fused surface radiation budget at $0.5^{\circ}$ over the TP has been developed, which addresses the relative low accuracy of surface radiation budget from individual remotesensing or reanalysis product and the sparse ground radiation measurements by integrating multiple data sets (Shi and Liang, 2013a). It is assumed that the latent heat flux and the net radiation from the previous study (Shi and Liang, 2013a) 
are more reliable than that of the sensible heat flux from multiple reanalysis and remote sensing. Therefore, the sensible heat flux was estimated from the energy balance (Eq. 1) by subtracting the latent heat and ground heat fluxes (this study) from the previously developed net radiation (Shi and Liang, 2013a). To ensure energy closure, only the stations with all SEB component measurements were used in the data fusion of the latent heat flux. Additional experiments were performed by applying the MLR to fuse the sensible heat flux directly from multiple data sets (ground observations, reanalysis and remote-sensing data sets) for comparison with the proposed surface energy balance approach. Three types of statistics - RMS error (RMSE), mean bias error (MBE), and coefficient of determination $\left(R^{2}\right)$ - were used to quantify the accuracy of each input product. The leave-one-siteout cross validation was conducted by applying the fusion model after removing a site and validating with the unused site. The root mean square error (RMSE) from cross validation (RMSE_CV) was computed as the average RMSE after applying this process multiple times (omitting one site for validation each time). RMSE_CV was used to validate the fused SEB components.

In the case of high-level data fusion for the SEB, such as feature-level image fusion according to Pohl and Van Genderen (1998), the MLR fused method constrains the error of the fused SEB through minimization of the residue error. To quantify the potential error from the selection of the data fusion method, experiments were conducted in which the same inputs were used for different linear regression models, including stepwise regression, which selects data sets by excluding those from the starting model to minimize the Bayesian information criterion (BIC); principle analysis regression (PCA), which inherits from the MLR but uses the first two or three principle components of input data sets (PCA_2 and PCA_3); and adapted lasso regression, which improves the lasso regularization technique in the selection of data sets to simultaneously estimate and select variables with adaptive weights (Zou, 2006). Advanced statistical methods with the potential for revealing unseen (i.e., nonlinear) processes by linear approximations were selected for comparison with the MLR results, including supported vector regression (SVM) (Vapnik, 1999) and random forest (RF) regression (Breiman, 2001). SVM computes optimized hyperplanes that maximize the deviations from the targets, which has been applied in the fusing of multiple remotesensing data sets in cases such fuel mapping and precipitation retrievals (García et al., 2011; Wei and Roan, 2012). RF realizes the concept of ensemble learning from the group of regression trees through processes of boosting and bagging. An additional commonly used method, particularly in multimodel fusion, is Bayesian model averaging (BMA), which was implemented to optimize weights to integrate predictive distributions from multi-models such as the mapping of longwave radiative fluxes from multiple models (Raftery et al., 2005; H. Wu et al., 2012).

\subsection{Spatiotemporal characterizations}

The spatial pattern of the seasonal and annual average and the standard deviation (STD) of the latent and sensible heat fluxes over the TP were analyzed. The four seasons were defined as spring (March-April-May), summer (June-JulyAugust), autumn (September-October-November), and winter (December-January-February). The seasonal and annual variability from the average latent and sensible heat-flux anomalies over the TP was compared to the selected indicators of atmospheric and surface conditions and the fused surface radiation budget anomalies (Shi and Liang, 2013b), the relationships of which were quantified by using the Pearson correlation coefficient. The selected variables included cloud cover and temperature (monthly mean of daily mean temperature and temperature range) from the Climate Research Unit (CRU) TS3.1 (Harris et al., 2014), Rutgers snow cover data (Robinson et al., 1993), the GIMMS AVHRR NDVI (Tucker et al., 2005), and MERRA water vapor.

\section{Results and discussions}

\subsection{Validation results}

The validation results of CFSR, MERRA, ERA-Interim, JRA-25, and Zhang10 are shown in Table 3. The latent heat flux from all four reanalysis products had significantly higher $R^{2}(>0.8)$ than those of sensible heat flux. CFSR underestimated latent and sensible heat fluxes by $-13.1 \mathrm{Wm}^{-2}$ and $-4.9 \mathrm{Wm}^{-2}$, respectively, and overestimated $\mathrm{G}$ by $6.6 \mathrm{Wm}^{-2}$. The RMSE of the latent heat flux from CFSR was the largest among all data sets. MERRA and JRA-25 overestimated the latent heat flux with RMSE by $15 \mathrm{Wm}^{-2}$. MERRA (JRA-25) exhibited the lowest $R^{2}$ (largest RMSE) in the sensible heat flux of all reanalysis data sets. Latent and sensible heat fluxes from the ERAInterim at $11.5 \mathrm{Wm}^{-2}$ and $20.5 \mathrm{Wm}^{-2}$, respectively were the most accurate among other products with the lowest RMSE. Zhang10 (GLEAM-LE) had a high $R^{2}$ by $0.89(0.90)$ but showed underestimation of $-12.0 \mathrm{Wm}^{-2}\left(-4.1 \mathrm{Wm}^{-2}\right)$ of the latent heat flux.

The coefficients and intercepts used to calculate the ground heat flux and the fused latent heat flux with and without Zhang10 were derived by using the MLR method (Table 4). GLEAM-LE and JRA-25 had the largest coefficient in the latent heat and ground heat fluxes, respectively. Under the condition such that Zhang10 was missing, ERAInterim and GLEAM-LE mainly dominated the fused latent heat flux. The fused sensible heat, latent heat, and ground heat fluxes exhibited the lowest RMSE_CVs over those by using individual data sets by $14.3 \mathrm{Wm}^{-2}, 10.3 \mathrm{Wm}^{-2}$, and $2.6 \mathrm{Wm}^{-2}$, respectively (Table 5). The cross-validation results support that no individual reanalysis data set is supreme in all SEB components and that a synthesized approach that 
Table 3. Validation results of the surface energy budget components of reanalysis and remote-sensing data sets by comparing with in situ observation.

\begin{tabular}{llrrrrrr}
\hline & & CFSR & MERRA & $\begin{array}{r}\text { ERA- } \\
\text { Interim }\end{array}$ & JRA-25 & Zhang10 & GLEAM-LE \\
& & & & & \\
\hline Sensible heat flux & RMSE $\left(\mathrm{Wm}^{-2}\right)$ & 22.0 & 28.7 & 20.5 & 29.9 & - & - \\
& MBE $\left(\mathrm{Wm}^{-2}\right)$ & -4.9 & 4.4 & -11.8 & -14.5 & - & - \\
& $R^{2}$ & 0.32 & 0.12 & 0.28 & 0.23 & - & - \\
\hline \multirow{2}{*}{ Latent heat flux } & RMSE $\left(\mathrm{Wm}^{-2}\right)$ & 23.8 & 15.4 & 11.5 & 15.0 & 22.1 & 12.6 \\
& MBE $\left(\mathrm{Wm}^{-2}\right)$ & -13.1 & 8.5 & -1.7 & 3.9 & -12.0 & -4.1 \\
& $R^{2}$ & 0.82 & 0.87 & 0.90 & 0.86 & 0.89 & 0.90 \\
\hline \multirow{2}{*}{ Ground heat flux } & RMSE $\left(\mathrm{Wm}^{-2}\right)$ & 11.9 & 6.3 & 10.4 & 8.5 & - & - \\
& MBE $\left(\mathrm{Wm}^{-2}\right)$ & 6.6 & -1.8 & 0.1 & -0.5 & - & - \\
& $R^{2}$ & 0.73 & 0.78 & 0.73 & 0.82 & - & - \\
\hline
\end{tabular}

uses MLR could be a feasible way for improving accuracy. After using data from all available stations, the plots in Fig. 2 compared the fused results with the ground measurements, which indicated that the latent heat flux was closer to the 1:1 line than the other two components. RMSEs of the fused latent heat flux, sensible heat flux, and ground heat flux were $6.9 \mathrm{Wm}^{-2}, 11.6 \mathrm{Wm}^{-2}$, and $2.4 \mathrm{Wm}^{-2}$, respectively. The $R^{2}$ of the fused sensible heat flux was significantly improved (0.67), which was higher than that of the applying MLR to multiple sensible heat-flux products directly. The accuracy of the data fusion method is sensitive to the training data, which explains the decreased value of RMSE from RMSE_CV. An independent validation of the sensible heat flux by using Yang09 also indicated that the fused $H$ had the lowest RMSE, by $15.6 \mathrm{Wm}^{-2}$, than that by using individual reanalysis or remote-sensing data set, which ranged from $22.1 \mathrm{Wm}^{-2}$ to $26.0 \mathrm{Wm}^{-2}$.

The largest absolute differences in RMSE_CV of latent and sensible heat fluxes between the MLR and other linear regression models are low, by $1.6 \mathrm{Wm}^{-2}$ and $2.1 \mathrm{Wm}^{-2}$, respectively (Table 5). The sensible heat flux from the MLR outperformed those from SVM, RF, and BMA, indicating that the MLR model can effectively achieve the goal of data integration in this study. Moreover, the limited accuracy improved by the three advanced models could be attributed to the extreme limited capability of the training stations to approximate true-state statistics. An alternative approach to estimate the sensible heat flux by fusing in situ, reanalysis, and remote-sensing data sets directly has a higher RMSE_CV (by $21.2 \mathrm{~W} \mathrm{~m}^{-2}$ ) than that by computing it from the surface energy balance. Compared with the fused result by only using only in situ and reanalysis data (MLR_RA in Table 5), the MLR model lowered the RMSE_CV by including the two remote-sensing products. Because the presented comparisons of various data fusion methods are empirical and do not include modeling, comparisons of the results with those from
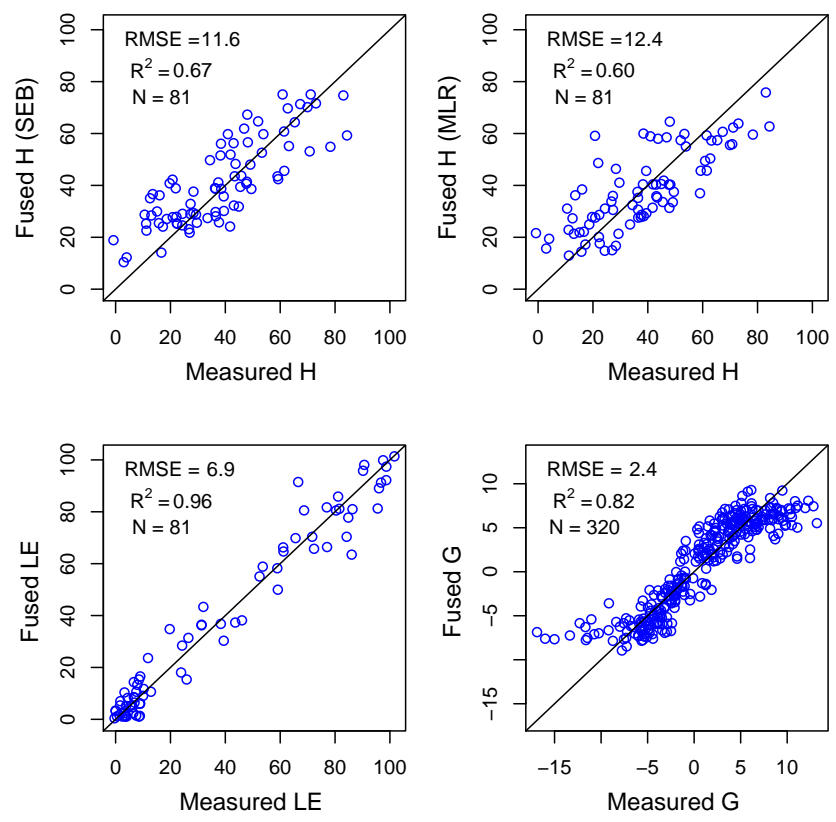

Figure 2. Comparisons of the measured and the predicted (fused) sensible heat flux $(H)$, latent heat flux (LE), and ground heat flux $(G)$ by Eq. (3) (SEB: estimating the sensible heat flux form the surface energy balance; MLR: applying multiple linear regression method to fuse multiple sensible heat data sets).

data assimilation techniques have not been conducted in this study and remain a key topics for future research.

A comparison was also performed with other global data sets that were available during the validation period (Table 5). The selected data sets include MERRALAND as the supplementary product, which uses the revised MERRA land system forced with observed precipitation (Reichle et al., 2011); a global land evapotranspiration data set reported by a Princeton University study on the basis of a revised Penman-Monteith model that used radiation-forcing data from GEWEX SRB 3.0 (PU-ET) (Mu et al., 2007; Vinukollu 
Table 4. Coefficients and intercept to calculate fused data by Eq. (3) (coefficients and intercepts with $p$ value $<0.05$ are in bold).

\begin{tabular}{|c|c|c|c|c|c|c|c|}
\hline & \multirow{2}{*}{$\frac{\text { Intercept }}{\left(\mathrm{Wm}^{-2}\right)}$} & \multicolumn{6}{|c|}{ Coefficients } \\
\hline & & CFSR & MERRA & $\begin{array}{r}\text { ERA } \\
\text { Interim }\end{array}$ & JRA-25 & Zhang10 & $\begin{array}{r}\text { GLEAM } \\
\text { LE }\end{array}$ \\
\hline Latent heat flux & $\begin{array}{l}-8.7994 \\
-5.6313 \\
-6.8247\end{array}$ & $\begin{array}{l}- \\
- \\
-\end{array}$ & $\begin{array}{l}0.4191 \\
0.2349 \\
0.2002\end{array}$ & $\begin{array}{l}0.5345 \\
0.4810 \\
0.3627\end{array}$ & $\begin{array}{c}\mathbf{0 . 1 9 6 1} \\
0.0153 \\
0.0599\end{array}$ & $\begin{array}{r}- \\
- \\
0.2762\end{array}$ & $\begin{array}{r}- \\
0.4418 \\
0.3923\end{array}$ \\
\hline Ground heat flux & 1.4429 & -0.0732 & 0.1422 & - & 0.3531 & - & - \\
\hline
\end{tabular}

Table 5. Comparison of the cross-validation results of the surface energy budget from the fused data, other data fusion approaches (MLR_RA: MLR using reanalysis data sets; stepwise: stepwise regression; lasso: adapted lasso regression; PCA_2: principle analysis regression using first two principle components; PCA_3: principle analysis regression using first three principle components; BMA: Bayesian model averaging; RF: random forest; SVM: supported vector regression), reanalysis, and remote-sensing data sets (* denotes results from fusing or calibrating the sensible heat flux from multiple data sets or single data set directly).

\begin{tabular}{lrrrr}
\hline Products & $\begin{array}{r}\text { Sensible heat flux } \\
\left(\mathrm{Wm}^{-2}\right)\end{array}$ & $\begin{array}{r}\text { Sensible heat flux* } \\
\left(\mathrm{Wm}^{-2}\right)\end{array}$ & $\begin{array}{r}\text { Latent heat flux } \\
\left(\mathrm{Wm}^{-2}\right)\end{array}$ & $\begin{array}{r}\text { Ground heat flux } \\
\left(\mathrm{Wm}^{-2}\right)\end{array}$ \\
\hline Fusion, MLR & 14.3 & 21.2 & 10.3 & 2.6 \\
Fusion, MLR_RA & 16.7 & 23.9 & 10.8 & 2.6 \\
Fusion, stepwise & 15.1 & 20.5 & 11.1 & 2.6 \\
Fusion, lasso & 14.3 & 20.6 & 11.2 & 2.6 \\
Fusion, PCA_2 & 14.8 & 24.5 & 8.7 & 2.6 \\
Fusion, PCA_3 & 14.4 & 24.6 & 9.5 & 2.6 \\
Fusion, BMA & 14.3 & 21.7 & 10.0 & 2.6 \\
Fusion, RF & 16.4 & 22.8 & 9.0 & 2.8 \\
Fusion,SVM & 15.9 & 22.5 & 9.1 & 2.7 \\
CFSR & 22.9 & 22.7 & 17.0 & 6.3 \\
MERRA & 25.6 & 26.6 & 14.1 & 10.4 \\
ERA-Interim & 30.4 & 22.9 & 11.5 & 8.5 \\
JRA-25 & 24.8 & 24.3 & 14.7 & - \\
Zhang10 & 18.7 & 20.8 & 14.7 & - \\
GLEAM-LE & 21.3 & 18.7 & 13.2 & 8.6 \\
GLADS-1-CLM & 27.5 & 25.8 & 16.9 & 9.4 \\
GLADS-1-MOS & 22.4 & 20.8 & 13.8 & 5.3 \\
GLADS-1-NOAH & 34.7 & 17.3 & 30.4 & 13.5 \\
GLADS-2-NOAH & 21.8 & 16.1 & 17.0 & 21.0 \\
NRA-1 & 74.1 & 21.0 & 59.0 & 18.9 \\
NRA-2 & 74.0 & 21.0 & 48.2 & - \\
PU-ET & 15.2 & 16.1 & 20.1 & \\
\hline
\end{tabular}

et al., 2011); and four data sets from the Global Land Data Assimilation Systems (Rodell et al., 2004), which uses three off-line models including the Common Land Model version 2.0 (GLDAS-1-CLM) (Oleson et al., 2004), the Mosaic Model (Koster and Suarez, 1996) (GLDAS-1-MOS), and the National Centers for Environmental Prediction/Oregon State University/Air Force/Hydrologic Research Lab Model version 2.7 (Chen et al., 1997; Ek et al., 2003) (GLDAS1-NOAH, GLDAS-2-NOAH). Overall, the fused latent and sensible heat fluxes outperformed those by using global data sets in terms of lower RMSE_CVs. Therefore, the validation and intercomparison of the SEB components should be im- plemented before applying global data sets for regional studies, especially over areas in which sparse ground observations are used to constrain the models or the parameterization of the land surface model is less tuned to adjust to the local conditions.

\subsection{Comparisons of seasonal and interannual variability}

The comparison with the ground observations of the monthly cycle averaged over all available stations showed more consistent seasonal cycles of latent heat and the ground heat fluxes than that of the sensible heat flux from reanalysis and 

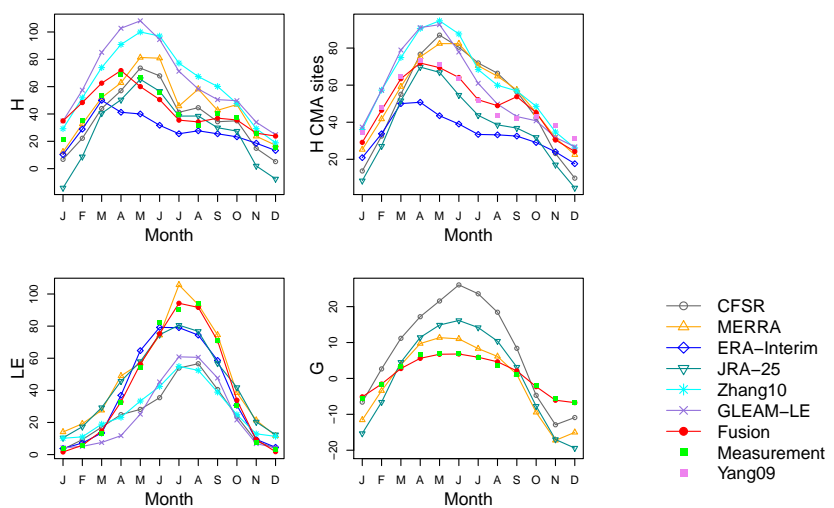

Figure 3. Monthly cycles of sensible heat flux $(H)$, latent heat flux (LE), and ground heat flux $(G)$ from multiple data sets and fused data with ground measurement averaged for all available sites (units are $\mathrm{Wm}^{-2}$ ).

remote-sensing data sets (Fig. 3). The ground heat flux from the reanalysis data sets had a positive (negative) bias in spring and summer (winter). MERRA, JRA-25, and Zhang10 overestimated the latent heat flux in winter, which was significantly underestimated by CFSR, Zhang10, and GLEAM-LE by $>20 \mathrm{Wm}^{-2}$ from May to September. Although the number of stations is small, the consistent seasonal cycles from remote-sensing and reanalysis data sets enhance the confidence for the climatology and monthly accuracy of latent heat flux over the central and eastern TP. MERRA exhibited large fluctuation for sensible heat flux in summer and autumn; CFSR and JRA-25 showed a similar pattern but with less value and variability; and Zhang10 and GLEAMLE (ERA-Interim) had a smooth variation with a peak in May (March). A comparison with the monthly cycles of CMA stations from Yang09 over bare land and sparsely vegetated areas indicates that the fused sensible heat flux was closer to that from Yang09, particularly from January to August. The differences in seasonal variability of the sensible heat flux in autumn and in early winter (when fused sensible heat flux is closer to the value from Zhang10, MERRA, and CFSR) may be related to the changes in samples of CMA stations in autumn to satisfy the bare land or sparsely vegetated conditions in addition to the scale discrepancy between the points and grids which varies as the sample changes.

The seasonal and annual anomalies of latent and sensible heat fluxes averaged over CMA stations from the fused data were compared with those from reanalysis, remote-sensing, and Yang11 data sets (Figs. 4 and 5). Because no direct measurement of the latent and sensible heat fluxes was possible over the CMA stations, the accuracy of the variation and trend from Yang11 could not be validated directly as was only compared with other data sets. Although the interannual variability of the latent heat flux in spring and winter and the sensible heat flux in all seasons except summer from CFSR were larger than those of other data sets, all data sets
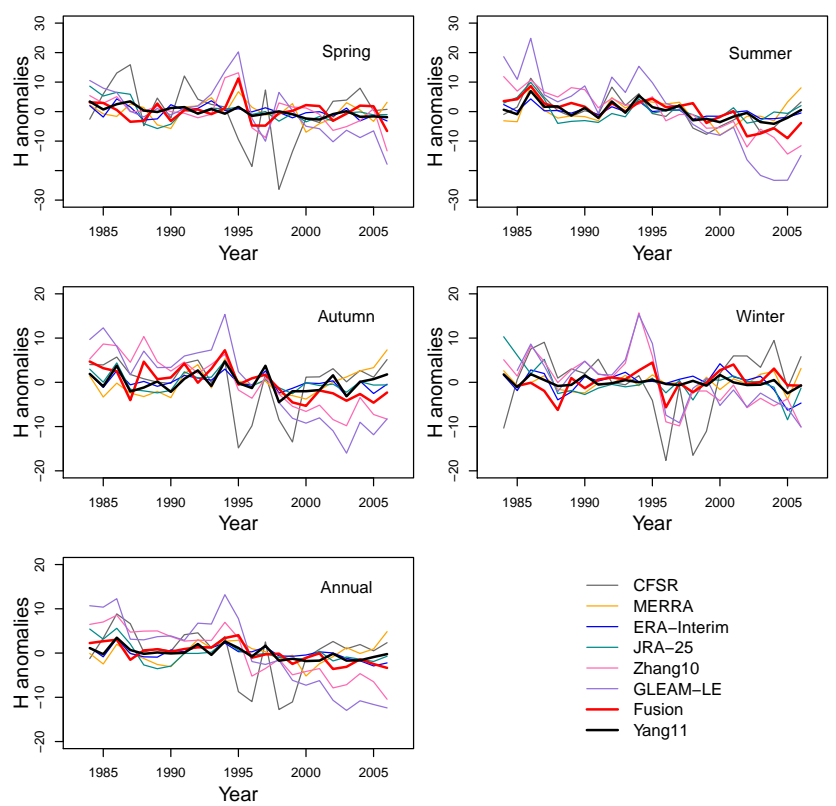

Figure 4. Anomalies of sensible heat flux from multiple data sets and fused data with ground measurement averaged for all available CMA stations (units are $\mathrm{Wm}^{-2}$ ).

showed consistent variation of latent heat flux in autumn and sensible heat flux in summer. The season with the weakest Pearson correlation of the sensible/latent heat flux between the fused data and Yang11 was spring, when divergences of anomalies among reanalysis, remote-sensing, and Yang11 were present. The potential causes of this phenomenon may include the weak correlation of albedo $(-0.15)$ and net radiation $(-0.02)$ between the fused net radiation and Yang11 (result not shown); the large uncertainty in modeling the SEB in spring, as indicated from the wide variety of multiple data sets; and the heterogeneity and physical effects such as soil moisture and albedo from snow cover changes. In addition, the annual latent heat-flux anomalies from the fused data were also compared with the inferred value by using the water balance method over two river basins over the TP. The water balance method estimated the annual latent heat flux over the upper Yellow River and the upper Yangtze River basins by subtracting the observed runoff at the Tangnanhai and Zhimenda hydrological stations from the total precipitation sourced from the gauge-based precipitation data set over East Asia (Xie et al., 2007), assuming that the change in the terrestrial water storage at the annual scale was negligible (Xue et al., 2013). The fused latent heat anomalies agreed with the water balance referred value over the upper Yangtze River basin with the Pearson correlation coefficient by 0.49 ( $p$ value $<0.1$ ), while neither the fused data nor the reanalysis or remote-sensing data sets was significantly correlated with the latent heat anomalies estimated from the water balance method over the upper Yellow River basin (Fig. 6). Overall, the fused sensible and latent heat-flux anomalies (averaged 

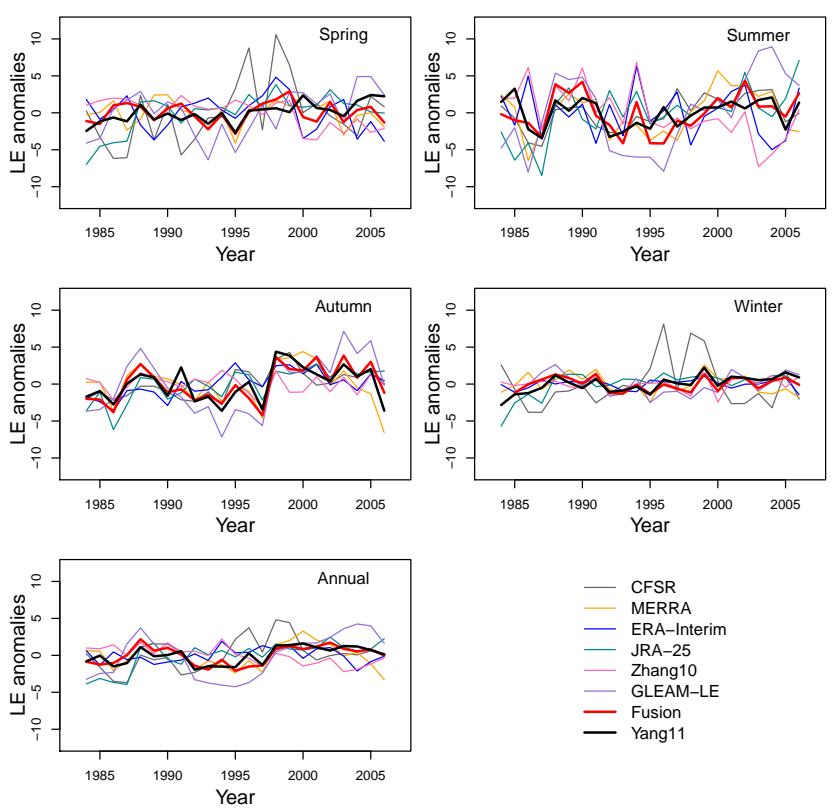

Figure 5. Anomalies of latent heat flux from multiple data sets and fused data with ground measurement averaged for all available CMA stations (units are $\mathrm{Wm}^{-2}$ ).
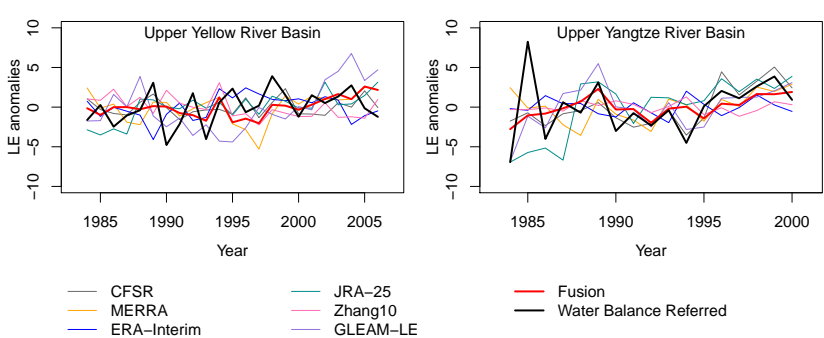

Figure 6. Anomalies of the annual basin average latent heat flux from multiple data sets and fused data with the water balance referred value over the upper Yellow River and upper Yangtze River basins (units are $\mathrm{Wm}^{-2}$ ).

over CMA stations) were consistent with that from Yang11 and the annual latent heat-flux anomalies displayed similar variation with that from the inferred value at the Yangtze River basin in addition to the highest accuracy according to the RMSE_CV (Sect. 4.1), which were used in the spatiotemporal analysis of the sensible and latent heat fluxes (Sects. 4.4 and 4.5).

\subsection{Uncertainties of the fused surface energy fluxes}

The varied uncertainties from inputs and methods by which the latent and sensible heat fluxes are estimated complicate the quality assessment of the SEB from stations, reanalysis, and remote-sensing data sets. Specifically, the input error of the fused SEB is referred to as errors from the monthly value for ground-measured, reanalysis, or remote-sensing data sets. Previous studies suggest that no single reanalysis data set is superior to others in terms of routinely measured surface variables such as temperature, precipitation, humidity, pressure, and wind speed and the surface radiation budget, which suggests divergent representation and parameterization of the diurnal cycles of surface variables such as ground-air temperature, wind speed, and aerodynamic roughness in the land surface models used to estimate the SEB (Wang and Zeng, 2012; Zhu et al., 2012). The uncertainty from Zhang 10 could be inherited through errors from the AVHRR GIMMS NDVI as inputs and the energy imbalance of eddy-covariance measurements as training samples (Zhang et al., 2010). Additional dominant input error is sourced from net radiation and downward shortwave irradiance, which largely determine the available energy to be partitioned into heat fluxes (Liang et al., 2014). The validation result also proves that accuracy of the latent heat flux is significantly higher than the sensible heat flux from reanalysis or remote sensing, which is possibly attributed to the estimation of the latent heat flux is constrained from not only the energy but also water balance over the TP (Mueller et al., 2013).

The uncertainty of the fused SEB is also affected by error propagation through calculations, including eddy-covariance retrieval, threshold filtering, averaging, interpolation, and data fusion. It is worth noting that eddy-covariance retrieval and MLR data fusion employ both multiplication and addition/subtraction, suggesting that uncertainty of the fused SEB could be amplified from those calculations. Nevertheless, the data fused approach is an applicable method for this regional application because of constraining the uncertainty by integrating ground measurement, reanalysis, and remotesensing products, which lowered the RMSE_CV than that by using each calibrated input data set (Table 5). In addition, the error of the fused data introduced by the resample scale is an emergent issue in the case of integrating synthesis that uses multiple data sets at various spatial resolutions. The impact of the resample scale has been assessed by applying the proposed data fusion method to seven grid sizes including $0.1^{\circ}, 0.3^{\circ}, 0.5^{\circ}, 1.0^{\circ}, 1.5^{\circ}, 2.0^{\circ}$, and $2.5^{\circ}$ to compare the sensitivity to the resample scale among the fused, reanalysis, and remote-sensing data sets (Fig. 7). The RMSE_CV of the ground heat flux and the sensible heat flux is less variable than that of the latent heat flux among the various scales. In addition, the robustness of fused latent and sensible heat fluxes is supported by lower variation in RMSE_CV with the decreased resample scale than by reanalysis and remote-sensing data sets. The magnitude of the changes in RMSE_CV $\left( \pm 2.5 \mathrm{Wm}^{-2}\right)$ resulting from the various resample scales below $1.5^{\circ}$ was less than that from the instrumental errors introduced in Sect. 2.1.

\subsection{Spatial and seasonal variability of the sensible heat flux}

The sensible heat flux was lower in summer than that in spring in the eastern TP, corresponding to the onset of the 

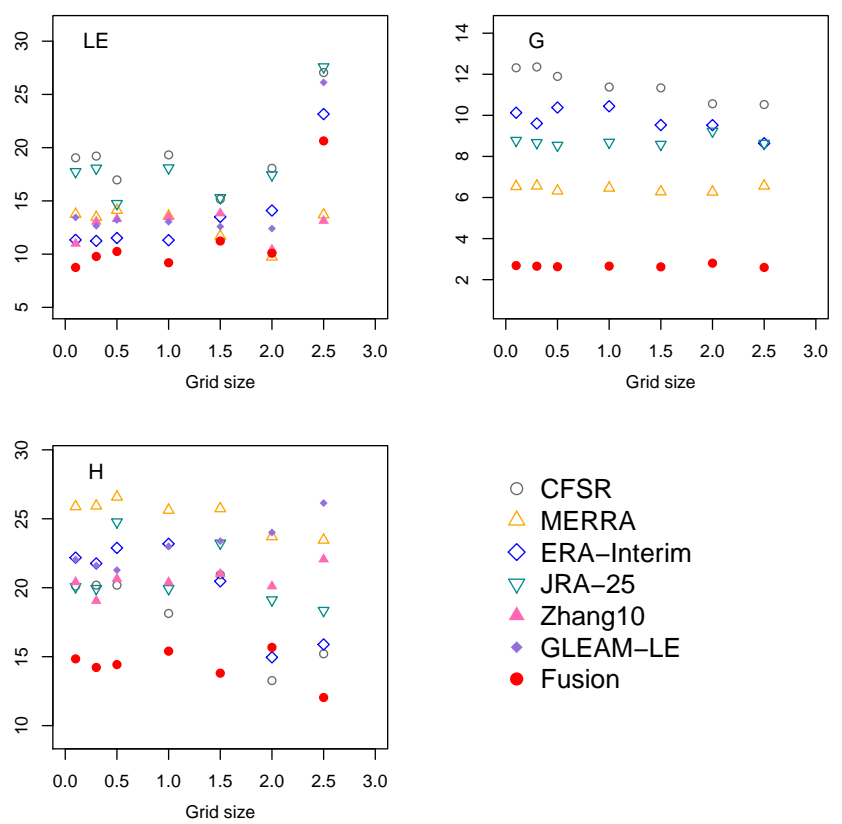

○ CFSR

$\triangle$ MERRA

$\diamond$ ERA-Interim

$\nabla$ JRA-25

$\triangle$ Zhang10

- GLEAM-LE

- Fusion

Figure 7. Comparisons of the RMSE_CV $\left(\mathrm{Wm}^{-2}\right)$ of latent heat flux (LE), ground heat flux $(G)$, and sensible heat flux $(H)$ at multiple grid sizes $\left(^{\circ}\right)$ from original data sets and fused data.

summer monsoon, as illustrated in Fig. 8. The sensible heat flux reached the lowest value in winter and decreased with latitude. In spring, summer, and autumn, the high values were located in the western plateau, the mountain ranges and basins of the western plateau, and the Himalaya ranges in the south TP, respectively. The annual STD was high in most dry area, including the northern ranges and basin and in the center of the western plateau. The high-STD area formed in the center of the western plateau in summer and moved to the northern ranges in autumn. The southeastern TP had a low STD in all seasons.

The temporal variations of sensible heat flux averaged over the TP correlated to cloud cover, water vapor, temperature anomalies, snow cover, and net radiative fluxes (Table 6). The sensible heat-flux anomalies correlated to the variations in the net shortwave or all-wave net radiation in all seasons, with the correlation coefficient reaching the maximum in spring. Thus, the following analysis focuses on cloud cover and water vapor, which are the two dominant factors that regulate the surface radiation budget and have the potential to be regulated by the feedback from local sensible heat fluxes (Shi and Liang, 2013b). The negative correlation between annual cloud cover and sensible heat flux was stronger in summer and winter than that from other seasons, which corresponding to the dominant role of cloud cover in regulating downward shortwave irradiance and net radiation. Positive correlation between the sensible heat flux and water vapor/temperature existed only in spring. In summer, the variability of the sensible heat-flux anomalies is negatively cor-
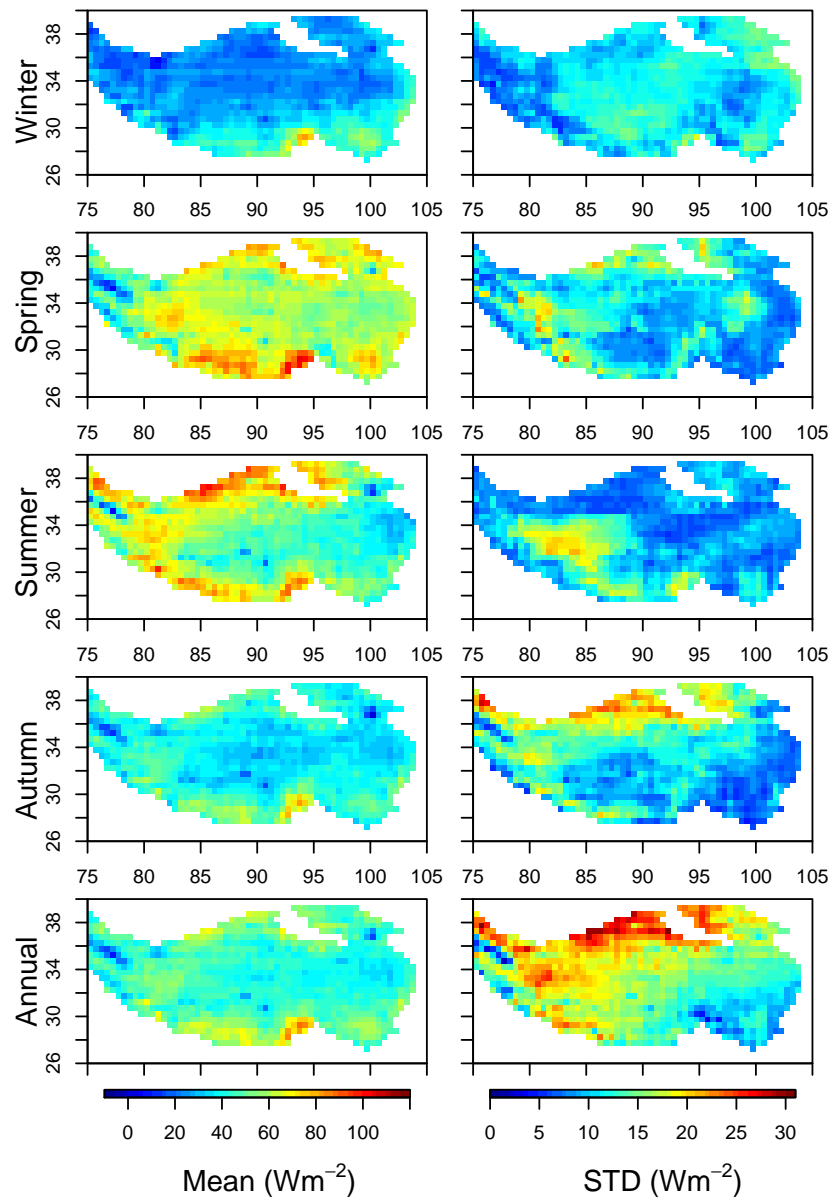

Figure 8. Spatial distribution of seasonal/annual mean and STD of the fused sensible heat flux over the TP (1984-2007).

related to that from water vapor and cloud cover by -0.60 and -0.41 , respectively. The correlation between the sensible heat flux and temperature over the TP suggests two possible physical links: the sensible heat flux mainly warms the surface air in spring as indicated from the positive correlation with mean temperature, and it is suppressed from the weakened temperature gradient in summer and autumn, as suggested from the negative (positive) correlation to mean temperature (temperature range).

\subsection{Spatial and seasonal variability of the latent heat flux}

The seasonal and annual mean and STD of the fused latent heat flux over the TP from 1984 to 2007 are shown in Fig. 9. The latent heat flux increased from northwest to southeast over the TP in all seasons. In summer, the high-mean value area was located in the eastern TP and in the southwest boundaries. STD was high (low) in the center of the western plateau in summer (spring). The annual STD is similar to that in autumn with high and low values in the center eastern and northern ranges of TP, respectively. In general, 
Table 6. Correlation coefficients between the annual and seasonal sensible and latent heat-flux anomalies from the fused data and surface and atmospheric anomalies over the TP (net shortwave (SW) and long wave (LW); all-wave radiation are from Shi and Liang, 2013a); $p$ value $<0.1$ are in bold).

\begin{tabular}{lrrrrr}
\hline & Annual & Spring & Summer & Autumn & Winter \\
\hline Sensible heat flux, cloud cover & -0.33 & -0.21 & $-\mathbf{0 . 4 1}$ & -0.31 & $-\mathbf{0 . 3 9}$ \\
Sensible heat flux, water vapor & $-\mathbf{0 . 4 2}$ & $\mathbf{0 . 4 0}$ & $-\mathbf{0 . 6 0}$ & -0.28 & -0.23 \\
Sensible heat flux, GIMMS NDVI & -0.05 & -0.19 & -0.25 & 0.33 & $\mathbf{0 . 4 5}$ \\
Sensible heat flux, temperature range & 0.29 & 0.18 & $\mathbf{0 . 6 8}$ & $\mathbf{0 . 5 9}$ & 0.05 \\
Sensible heat flux, mean temperature & $-\mathbf{0 . 4 8}$ & 0.33 & $-\mathbf{0 . 5 3}$ & $-\mathbf{0 . 5 5}$ & -0.25 \\
Sensible heat flux, snow cover & -0.16 & 0.30 & 0.08 & -0.11 & 0.03 \\
Sensible heat flux, net SW radiation & $\mathbf{0 . 6 6}$ & $\mathbf{0 . 8 0}$ & $\mathbf{0 . 8 1}$ & $\mathbf{0 . 4 9}$ & $\mathbf{0 . 5 4}$ \\
Sensible heat flux, net LW radiation & -0.04 & -0.03 & $-\mathbf{0 . 5 7}$ & -0.07 & -0.18 \\
Sensible heat flux, net radiation & $\mathbf{0 . 8 3}$ & $\mathbf{0 . 9 6}$ & $\mathbf{0 . 8 1}$ & $\mathbf{0 . 7 2}$ & $\mathbf{0 . 9 0}$ \\
Latent heat flux, cloud cover & $\mathbf{0 . 5 0}$ & 0.33 & 0.33 & 0.34 & $\mathbf{0 . 3 9}$ \\
Latent heat flux, water vapor & $\mathbf{0 . 7 3}$ & 0.16 & $\mathbf{0 . 5 1}$ & $\mathbf{0 . 7 7}$ & $\mathbf{0 . 5 7}$ \\
Latent heat flux, GIMMS NDVI & $\mathbf{0 . 4 8}$ & $\mathbf{0 . 4 6}$ & $\mathbf{0 . 6 0}$ & 0.29 & 0.29 \\
Latent heat flux, temperature range & $-\mathbf{0 . 5 2}$ & -0.21 & $-\mathbf{0 . 3 8}$ & $-\mathbf{0 . 3 8}$ & -0.25 \\
Latent heat flux, mean temperature & $\mathbf{0 . 5 9}$ & -0.15 & $\mathbf{0 . 4 9}$ & $\mathbf{0 . 8 5}$ & $\mathbf{0 . 4 0}$ \\
Latent heat flux, maximum temperature & $\mathbf{0 . 4 4}$ & -0.18 & 0.25 & $\mathbf{0 . 7 5}$ & 0.27 \\
Latent heat flux, snow cover & $\mathbf{0 . 3 6}$ & 0.12 & -0.07 & -0.06 & -0.08 \\
Latent heat flux, net SW radiation & -0.28 & -0.18 & -0.33 & -0.07 & -0.06 \\
Latent heat flux, net LW radiation & $\mathbf{0 . 3 8}$ & 0.32 & $\mathbf{0 . 4 5}$ & 0.15 & 0.06 \\
Latent heat flux, net radiation & 0.02 & 0.00 & -0.05 & 0.09 & -0.03 \\
\hline
\end{tabular}

the climatology of mean and STD of latent heat flux corresponded to the elevation from the northwestern to southeastern TP and to the dry and wet climate in the western and eastern TP.

The interannual variation of the latent heat flux over the TP has been compared with atmospheric and surface conditions and surface net radiative fluxes that may regulate the latent heat flux (Wang and Liang, 2008; Wang and Dickinson, 2012). In summer, autumn and winter, interannual variation of the latent heat flux correlated strongly to that from water vapor, with correlation coefficients of $0.51,0.77$, and 0.57 , respectively (Table 6). The seasonal variation of latent heat flux was inherited from the NDVI anomalies as input to the Zhang 10 with highest $R^{2}$ in summer of 0.60 , suggesting the importance of vegetation for regulating regional latent heat flux during the growing seasons. The weak correlation between the cloud cover/water vapor and latent heat flux in spring indicates a potential change in the dominant physical mechanism that determines the variation of latent heat flux from other seasons according to such factors as cloud depth or duration, wind speed, solar irradiance, and vegetation conditions. In general, the latent heat-flux anomalies are likely most associated with interannual variation of water vapor (except in spring), which is related to the surface water vapor pressure and moisture feedbacks to the atmosphere, whereas the maximum temperature act only as significant factors for latent heat-flux anomalies in autumn and at the annual scale, respectively.

\subsection{Implications for land-biosphere-atmosphere interactions and climate change}

The fused sensible and latent heat fluxes prompt interest in further understanding of the changes in land-biosphereatmosphere interactions over the TP. Applying remotesensing observations in land surface modeling enables the quantification of the SEB at the spatial continuous scale to be extended to the satellite era over two decades, which is otherwise impossible when using ground observations at the footprint scale alone. The seasonal dependence, as indicated from the correlation among surface-sensible and/or latent heat flux and cloud cover, water vapor, temperature, and temperature range, suggests that regional land-biosphere-atmosphere interactions may be associated with the advance and retreat of the summer and winter monsoon. The mechanisms by which land-biosphere-atmosphere interactions mitigate or amplify the anomalies of the surface latent and sensible heat flux over the TP have received little attention; therefore, future investigation should address this challenge by using models capable of reproducing past climate changes and variation of the surface heat fluxes over the TP.

\section{Conclusions}

The spatial and seasonal variability of the surface-sensible and latent heat fluxes over the TP from 1984 to 2007 was presented by using the fused monthly latent and sensible heat fluxes at $0.5^{\circ}$ from ground-measured data sets including 

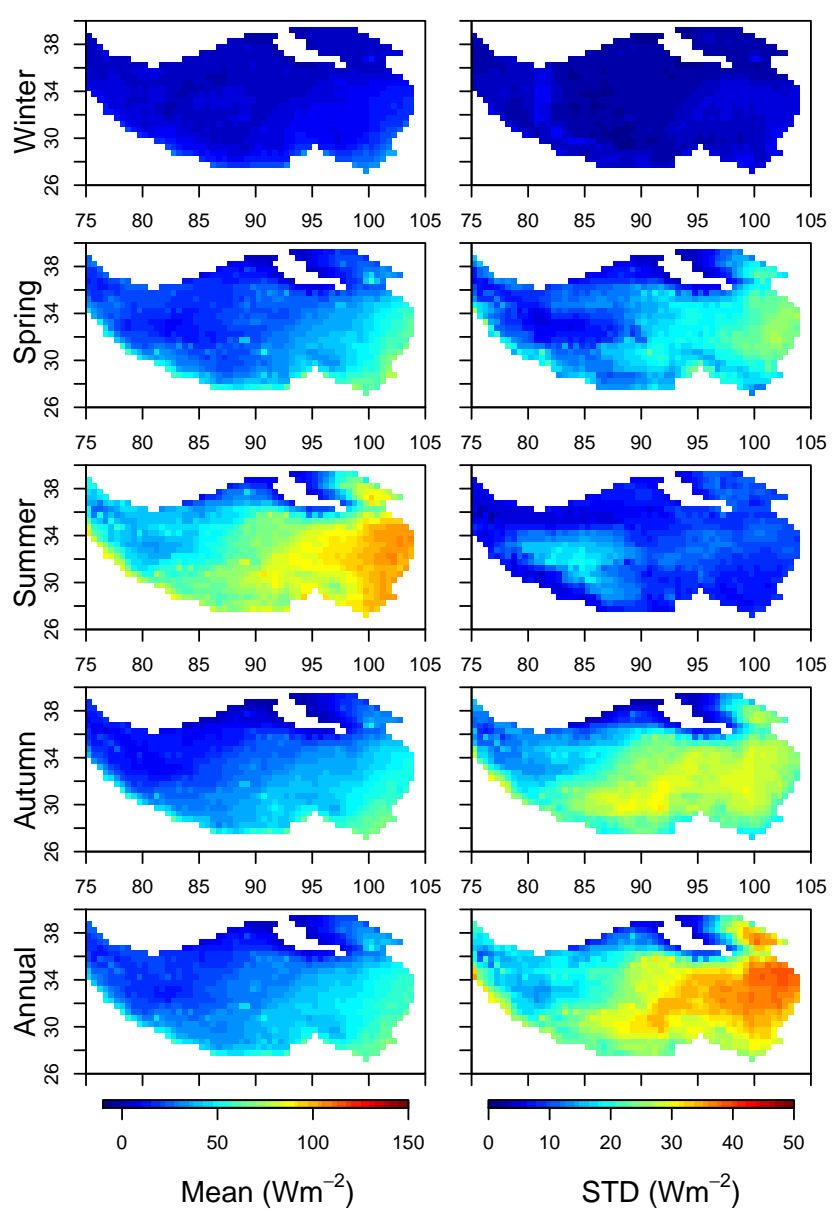

Figure 9. Spatial distribution of the seasonal/annual mean and STD of the fused latent heat flux over the TP (1984-2007).

AsiaFlux, ChinaFLUX, GAME/Tibet, and CAMP/Tibet; remote-sensing data sets from Zhang10 and GLEAM-LE; and reanalysis data sets including CFSR, MERRA, ERAInterim, and JRA-25. The surface-sensible and latent heat fluxes from reanalysis and remote-sensing data sets were first validated against those from ground measurement at the monthly scale and were then synthesized by using the multiple linear regression approach. The energy balance was closed at the daily scale to reduce uncertainties evolving in the diurnal cycles over the TP stations. The uncertainties of the fused surface-sensible and latent heat fluxes were discussed from various aspects in which uncertainties propagating from input errors and instrumental errors were likely the dominant factors when comparing with that from the interpolation scale and the selection of the fusion method. Results from the leave-one-site-out cross validation suggest that the fused monthly latent and sensible heat fluxes had the lowest RMSE_CVs, at $10.3 \mathrm{Wm}^{-2}$ and $14.3 \mathrm{Wm}^{-2}$, respectively, against those using each calibrated data set. In addition, the fused sensible heat flux consistently captured the monthly cy- cle to the data sets by using only meteorological observations at CMA stations (Yang09).

At the regional scale, the latent and sensible heat fluxes displayed different seasonal evolution and distribution patterns, which are likely associated with latitudinal gradient, elevation difference, and monsoon climate over the TP. The highest value area of latent heat flux was located in the east TP and the south face of the southwest ranges, which are largely affected by the summer monsoon, whereas the sensible heat flux was high the middle-northern ranges, which are dry in spring and summer. The derived spatial pattern of the sensible and latent heat flux requires further validation over the western TP since uncertainties could be very large over area without any calibration sites.

The interannual anomalies of the latent and sensible heat fluxes averaged over the TP were explained through Pearson correlation analysis including such factors as cloud cover, water vapor, NDVI, snow cover, temperature, maximum temperature, and temperature range. A strong correlation between latent heat flux and water vapor existed in all seasons except spring, whereas a strong high correlation to sensible heat flux existed in spring and summer but in opposite directions. During summer, the number of significant correlated variables with the sensible and latent heat fluxes was the largest, and the magnitude of most correlations was also the largest for all seasons. These results imply that the coherent changes in the surface and atmospheric variables could relate to decadal changes over the TP by influencing the surface radiation budget, transpiration (evaporation) of vegetation (soil), or temperature gradient. Such results confirm that land-biosphere-atmosphere interactions may regulate the temporal variation of the surface-sensible and latent heat fluxes, although the magnitude of such couplings has seasonal dependence. Because approximately one-fourth of the world's population is affected by the East Asian monsoon, which is fueled by sensible and latent heat fluxes over the TP, it would be interesting to quantify the drivers and responses of the changes in surface-sensible and latent heat fluxes in future research by using numerical modeling.

Acknowledgements. This study is funded by the National Oceanic and Atmospheric Administration (NOAA). We are grateful to researchers from AsiaFlux, ChinaFLUX, GAME/Tibet, CEOP/Tibet, and NMIC/CMA for providing ground observation data over the TP. The CFSR and JRA data are from the Research Data Archive (RDA), which is maintained by the Computational and Information Systems Laboratory (CISL) at the National Center for Atmospheric Research (NCAR). We thank the Global Modeling and Assimilation Office (GMAO) and the GES DISC for the dissemination of MERRA, ECMWF data server for ERA Interim, and the University of Montana Numerical Terradynamic Simulation Group for Zhang10. We acknowledge researchers from the Princeton University terrestrial hydrology research group for proving the PU-ET, NASA Global Inventory Modeling and Mapping Studies (GIMMS) for providing the AVHRR GIMMS NDVI, the British 
Atmospheric Data Centre (BADC) for providing CRU TS3.1 temperature and cloud cover, and the Rutgers University Global Snow Lab for providing Northern Hemisphere snow cover. The GLDAS data are acquired as part of a mission of NASA's Earth Science Division and archived and distributed by the Goddard Earth Sciences (GES) Data and Information Services Center (DISC), NRA-1 and NRA-2 are from the NOAA/OAR/ESRL PSD. A special thanks to Kun Yang who has provided not only Yang09 and Yang11 data sets and but also constructive comments. We thank D. G. Miralles (University of Bristol) and J. Fisher (NASA Jet Propulsion Laboratory) for the provision of GLEAM-LE and PU-ET.

Edited by: J.-Y. C. Chiu

\section{References}

An, Z., Kutzbach, J. E., Prell, W. L., and Porter, S. C.: Evolution of Asian monsoons and phased uplift of the HimalayaTibetan Plateau since Late Miocene times, Nature, 411, 62-66, doi:10.1038/35075035, 2001.

Baldocchi, D., Falge, E., Gu, L., Olson, R., Hollinger, D., Running, S., Anthoni, P., Bernhofer, C., Davis, K., Evans, R., Fuentes, J., Goldstein, A., Katul, G., Law, B., Lee, X., Malhi, Y., Meyers, T., Munger, W., Oechel, W., Paw, K. T., Pilegaard, K., Schmid, H. P., Valentini, R., Verma, S., Vesala, T., Wilson, K., and Wofsy, S.: FLUXNET: a new tool to study the temporal and spatial variability of ecosystemscale carbon dioxide, water vapor, and energy flux densities, B. Am. Meteorol. Soc., 82, 2415-2434, doi:10.1175/15200477(2001)082<2415:FANTTS>2.3.CO;2, 2001.

Bian, L., Gao, Z., Ma, Y., Koike, T., Ma, Y., Li, Y., Sun, J., Hu, $\mathrm{Z}$., and $\mathrm{Xu}, \mathrm{X}$.: Seasonal variation in turbulent fluxes over Tibetan Plateau and its surrounding areas: research note, J. Meteorol. Soc. Jpn., 90C, 157-171, doi:10.2151/jmsj.2012-C11, 2012.

Breiman, L.: Random Forests, Mach. Learn., 45, 5-32, doi:10.1023/a:1010933404324, 2001.

Chen, F., Janjić, Z., and Mitchell, K.: Impact of atmospheric surface-layer parameterizations in the new land-surface scheme of the NCEP Mesoscale Eta Model, Bound.-Lay. Meteorol., 85, 391-421, doi:10.1023/a:1000531001463, 1997.

Chen, M., Shi, W., Xie, P., Silva, V. B. S., Kousky, V. E., Higgins, R. W., and Janowiak, J. E.: Assessing objective techniques for gauge-based analyses of global daily precipitation, J. Geophys. Res.-Atmos., 113, D04110, doi:10.1029/2007jd009132, 2008.

Chen, X., Su, Z., Ma, Y., and Sun, F.: Analysis of land-atmosphere interactions over the north region of Mt. Qomolangma (Mt. Everest), Arct. Antarct. Alp. Res., 44, 412-422, doi:10.1657/19384246-44.4.412, 2012.

Chen, X., Su, Z., Ma, Y., Yang, K., and Wang, B.: Estimation of surface energy fluxes under complex terrain of Mt. Qomolangma over the Tibetan Plateau, Hydrol. Earth Syst. Sci., 17, 16071618, doi:10.5194/hess-17-1607-2013, $2013 \mathrm{a}$.

Chen, X., Su, Z., Ma, Y., Yang, K., Wen, J., and Zhang, Y.: An improvement of roughness height parameterization of the Surface Energy Balance System (SEBS) over the Tibetan Plateau, J. Appl. Meteorol. Clim., 52, 607-622, doi:10.1175/jamc-d-12056.1, 2013b.
Chen, Y., Yang, K., Zhou, D., Qin, J., and Guo, X.: Improving the Noah land surface model in arid regions with an appropriate parameterization of the thermal roughness length, J. Hydrometeorol., 11, 995-1006, doi:10.1175/2010jhm1185.1, 2010.

Dee, D., Uppala, S. M., Simmons, A. J., Berrisford, P., Poli, P., Kobayashi, S., Andrae, U., Balmaseda, M. A., Balsamo, G., Bauer, P., Bechtold, P., Beljaars, A. C. M., van de Berg, L., Bidlot, J., Bormann, N., Delsol, C., Dragani, R., Fuentes, M., Geer, A. J., Haimberger, L., Healy, S. B., Hersbach, H., Hólm, E. V., Isaksen, L., Kållberg, P., Köhler, M., Matricardi, M., McNally, A. P., Monge-Sanz, B. M., Morcrette, J. J., Park, B. K., Peubey, C., de Rosnay, P., Tavolato, C., Thépaut, J. N., and Vitart, F.: The ERA-Interim reanalysis: configuration and performance of the data assimilation system, Q. J. Roy. Meteor. Soc., 137, 553-597, doi:10.1002/qj.828, 2011.

Douville, H., Royer, J. F., and Mahfouf, J. F.: A new snow parameterization for the Météo-France climate model, Clim. Dynam. 12, 21-35, doi:10.1007/bf00208760, 1995.

Douville, H., Viterbo, P., Mahfouf, J.-F., and Beljaars, A. C. M.: Evaluation of the optimum interpolation and nudging techniques for soil moisture analysis using FIFE data, Mon. Weather Rev., 128, 1733-1756, doi:10.1175/15200493(2000)128<1733:eotoia>2.0.co;2, 2000.

Duan, A., Wang, M., Lei, Y., and Cui, Y.: Trends in summer rainfall over China associated with the Tibetan Plateau sensible heat source during 1980-2008, J. Climate, 26, 261-275, doi:10.1175/jcli-d-11-00669.1, 2013.

Ek, M. B., Mitchell, K. E., Lin, Y., Rogers, E., Grunmann, P., Koren, V., Gayno, G., and Tarpley, J. D.: Implementation of Noah land surface model advances in the National Centers for Environmental Prediction operational mesoscale Eta model, J. Geophys. Res.-Atmos., 108, 8851, doi:10.1029/2002jd003296, 2003.

Ferguson, C. R. and Wood, E. F.: An Evaluation of Satellite Remote Sensing Data Products for Land Surface Hydrology: Atmospheric Infrared Sounder, J. Hydrometeorol., 11, 1234-1262, doi:10.1175/2010JHM1217.1, 2010.

Foken, T.: The energy balance closure problem: an overview, Ecol. Appl., 18, 1351-1367, doi:10.1890/06-0922.1, 2008.

Foken, T., Wimmer, F., Mauder, M., Thomas, C., and Liebethal, C.: Some aspects of the energy balance closure problem, Atmos. Chem. Phys., 6, 4395-4402, doi:10.5194/acp-6-4395-2006, 2006.

García, M., Riaño, D., Chuvieco, E., Salas, J., and Danson, F. M.: Multispectral and LiDAR data fusion for fuel type mapping using support vector machine and decision rules, Remote Sens. Environ., 115, 1369-1379, doi:10.1016/j.rse.2011.01.017, 2011.

Gu, S., Tang, Y. H., Cui, X. Y., Kato, T., Du, M. Y., Li, Y. N., and Zhao, X. Q.: Energy exchange between the atmosphere and a meadow ecosystem on the Qinghai-Tibetan Plateau, Agr. Forest Meteorol., 129, 175-185, doi:10.1016/j.agrformet.2004.12.002, 2005.

Guo, D., Yang, M., and Wang, H.: Characteristics of land surface heat and water exchange under different soil freeze/thaw conditions over the central Tibetan Plateau, Hydrol. Process., 25, 2531-2541, doi:10.1002/hyp.8025, 2011a.

Guo, X., Yang, K., and Chen, Y.: Weakening sensible heat source over the Tibetan Plateau revisited: effects of the landatmosphere thermal coupling, Theor. Appl. Climatol., 104, 1-12, doi:10.1007/s00704-010-0328-1, 2011b. 
Harris, I., Jones, P. D., Osborn, T. J., and Lister, D. H.: Updated high-resolution grids of monthly climatic observations - the CRU TS3.10 Dataset, Int. J. Climatol., 34, 623-642, doi:10.1002/joc.3711, 2014.

Immerzeel, W. W., van Beek, L. P. H., and Bierkens, M. F. P.: Climate change will affect the Asian water towers, Science, 328, 1382-1385, doi:10.1126/science.1183188, 2010.

Jiménez, C., Prigent, C., and Aires, F.: Toward an estimation of global land surface heat fluxes from multisatellite observations, J. Geophys. Res., 114, D06305, doi:10.1029/2008jd011392, 2009.

Jiménez, C., Prigent, C., Mueller, B., Seneviratne, S. I., McCabe, M. F., Wood, E. F., Rossow, W. B., Balsamo, G., Betts, A. K., Dirmeyer, P. A., Fisher, J. B., Jung, M., Kanamitsu, M., Reichle, R. H., Reichstein, M., Rodell, M., Sheffield, J., Tu, K., and Wang, K.: Global intercomparison of 12 land surface heat flux estimates, J. Geophys. Res., 116, D02102, doi:10.1029/2010jd014545, 2011.

Jung, M., Reichstein, M., and Bondeau, A.: Towards global empirical upscaling of FLUXNET eddy covariance observations: validation of a model tree ensemble approach using a biosphere model, Biogeosciences, 6, 2001-2013, doi:10.5194/bg-6-20012009, 2009.

Jung, M., Reichstein, M., Ciais, P., Seneviratne, S. I., Sheffield, J., Goulden, M. L., Bonan, G., Cescatti, A., Chen, J., de Jeu, R., Dolman, A. J., Eugster, W., Gerten, D., Gianelle, D., Gobron, N., Heinke, J., Kimball, J., Law, B. E., Montagnani, L., Mu, Q., Mueller, B., Oleson, K., Papale, D., Richardson, A. D., Roupsard, O., Running, S., Tomelleri, E., Viovy, N., Weber, U., Williams, C., Wood, E., Zaehle, S., and Zhang, K.: Recent decline in the global land evapotranspiration trend due to limited moisture supply, Nature, 467, 951-954, doi:10.1038/nature09396, 2010.

Jung, M., Reichstein, M., Margolis, H. A., Cescatti, A., Richardson, A. D., Arain, M. A., Arneth, A., Bernhofer, C., Bonal, D., Chen, J., Gianelle, D., Gobron, N., Kiely, G., Kutsch, W., Lasslop, G., Law, B. E., Lindroth, A., Merbold, L., Montagnani, L., Moors, E. J., Papale, D., Sottocornola, M., Vaccari, F., and Williams, C.: Global patterns of land-atmosphere fluxes of carbon dioxide, latent heat, and sensible heat derived from eddy covariance, satellite, and meteorological observations, J. Geophys. Res., 116, G00J07, doi:10.1029/2010jg001566, 2011.

Kalnay, E., Kanamitsu, M., Kistler, R., Collins, W., Deaven, D., Gandin, L., Iredell, M., Saha, S., White, G., Woollen, J., Zhu, Y., Leetmaa, A., Reynolds, R., Chelliah, M., Ebisuzaki, W., Higgins, W., Janowiak, J., Mo, K. C., Ropelewski, C., Wang, J., Jenne, R., and Joseph, D.: The NCEP/NCAR 40-year reanalysis project, B. Am. Meteorol. Soc., 77, 437-471, doi:10.1175/15200477(1996)077<0437:tnyrp>2.0.co;2, 1996.

Kiehl, J. T. and Trenberth, K. E.: Earth's annual global mean energy budget, B. Am. Meteorol. Soc., 78, 197-208, doi:10.1175/15200477(1997)078<0197:eagmeb>2.0.co;2, 1997.

Kim, J., Miyata, A., and Yu, G.: AsiaFlux-sustaining ecosystems and people through resilience thinking, WCC-3 Climate Sense, Tudor Rose, Leicester, 164-168, 2009.

Koike, T.: The Coordinated Enhanced Observing Period-An initial step for integrated global water cycle observation, WMO Bull., 53, 115-121, 2004.
Koster, R. D. and Suarez, M. J.: Energy and water balance calculations in the Mosaic LSM. NASA Tech. Memo. 104606, 9, 76 pp., NASA Goddard Space Flight Center, Greenbelt, 1996.

Koster, R. D., Suarez, M. J., Ducharne, A., Stieglitz, M., and Kumar, P.: A catchment-based approach to modeling land surface processes in a general circulation model: 1 . Model structure, J. Geophys. Res.-Atmos., 105, 24809-24822, doi:10.1029/2000jd900327, 2000.

Kutzbach, J. E., Prell, W. L., and Ruddiman, W. F.: Sensitivity of Eurasian climate to surface uplift of the Tibetan Plateau, J. Geol., 101, 177-190, doi:10.1086/648215, 1993.

Lee, J. H., Timmermans, J., Su, Z., and Mancini, M.: Calibration of aerodynamic roughness over the Tibetan Plateau with Ensemble Kalman Filter analysed heat flux, Hydrol. Earth Syst. Sci., 16, 4291-4302, doi:10.5194/hess-16-4291-2012, 2012.

Li, Z., Yu, G., Wen, X., Zhang, L., Ren, C., and Fu, Y.: Energy balance closure at ChinaFLUX sites, Sci. China Ser. D., 48, 51$62,2005$.

Liang, S., Wang, K., Zhang, X., and Wild, M.: Review on estimation of land surface radiation and energy budgets from ground measurement, remote sensing and model simulations, IEEE J. Sel. Top. Appl., 3, 225-240, doi:10.1109/JSTARS.2010.2048556, 2010.

Liang, S., Zhao, X., Liu, S., Yuan, W., Cheng, X., Xiao, Z., Zhang, X., Liu, Q., Cheng, J., Tang, H., Qu, Y., Bai, Y., Qu, Y., Ren, H., Yu, K., and Townshend, J.: A long-term Global LAnd Surface Satellite (GLASS) dataset for environmental studies, Int. J. Digit. Earth, 6, 5-33, doi:10.1080/17538947.2013.805262, 2013.

Liu, S., Li, S.-G., Yu, G.-R., Sun, X.-M., Zhang, L.-M., Hu, Z.-M., Li, Y.-N., and Zhang, X.-Z.: Surface energy exchanges above two grassland ecosystems on the Qinghai-Tibetan Plateau, Biogeosciences Discuss., 6, 9161-9192, doi:10.5194/bgd-6-9161-2009, 2009.

Liu, Y., Wu, G., Hong, J., Dong, B., Duan, A., Bao, Q., and Zhou, L.: Revisiting Asian monsoon formation and change associated with Tibetan Plateau forcing: II. Change, Clim. Dynam., 39, 1183-1195, doi:10.1007/s00382-012-1335-y, 2012.

Ma, Weiqiang, Ma, Yaoming, Li, Maoshan, Hu, Zeyong, Zhong, Lei, Su, Zhongbo, Ishikawa, Hirohiko, and Wang, Jiemin: Estimating surface fluxes over the north Tibetan Plateau area with ASTER imagery, Hydrol. Earth Syst. Sci., 13, 57-67, doi:10.5194/hess-13-57-2009, 2009.

Ma, W., Ma, Y., and Su, B.: Feasibility of retrieving land surface heat fluxes from ASTER data using SEBS: a case study from the NamCo area of the Tibetan Plateau, Arct. Antarct. Alp. Res., 43, 239-245, doi:10.1657/1938-4246-43.2.239, 2011.

Ma, Y., Su, Z., Koike, T., Yao, T., Ishikawa, H., Ueno, K., and Menenti, M.: On measuring and remote sensing surface energy partitioning over the Tibetan Plateau-From GAME/Tibet to CAMP/Tibet, Phys. Chem. Earth, 28, 63-74, doi:10.1016/s14747065(03)00008-1, 2003.

Ma, Y., Zhong, L., Su, Z., Ishikawa, H., Menenti, M., and Koike, T.: Determination of regional distributions and seasonal variations of land surface heat fluxes from Landsat-7 Enhanced Thematic Mapper data over the central Tibetan Plateau area, J. Geophys. Res., 111, D10305, doi:10.1029/2005jd006742, 2006.

Ma, Y., Zhong, L., Wang, B., Ma, W., Chen, X., and Li, M.: Determination of land surface heat fluxes over heterogeneous landscape of the Tibetan Plateau by using the MODIS and in situ 
data, Atmos. Chem. Phys., 11, 10461-10469, doi:10.5194/acp11-10461-2011, 2011.

Ma, Y., Zhong, L., Wang, Y., and Su, Z.: Using NOAA/AVHRR data to determine regional net radiation and soil heat fluxes over the heterogeneous landscape of the Tibetan Plateau, Int. J. Remote Sens., 33, 4784-4795, doi:10.1080/01431161.2011.638333, 2012.

Manabe, S. and Terpstra, T. B.: The effects of mountains on the general circulation of the atmosphere as identified by numerical experiments, J. Atmos. Sci., 31, 3-42, doi:10.1175/15200469(1974)031<0003:TEOMOT>2.0.CO;2, 1974.

Meng, J., Yang, R., Wei, H., Ek, M., Gayno, G., Xie, P., and Mitchell, K.: The land surface analysis in the NCEP Climate Forecast System Reanalysis, J. Hydrometeorol., 13, 1621-1630, doi:10.1175/jhm-d-11-090.1, 2012.

Miralles, D. G., Holmes, T. R. H., De Jeu, R. A. M., Gash, J. H., Meesters, A. G. C. A., and Dolman, A. J.: Global land-surface evaporation estimated from satellite-based observations, Hydrol. Earth Syst. Sci., 15, 453-469, doi:10.5194/hess-15-453-2011, 2011a.

Miralles, D. G., De Jeu, R. A. M., Gash, J. H., Holmes, T. R. H., and Dolman, A. J.: Magnitude and variability of land evaporation and its components at the global scale, Hydrol. Earth Syst. Sci., 15, 967-981, doi:10.5194/hess-15-967-2011, 2011 b.

Miralles, D. G., van den Berg, M. J., Gash, J. H., Parinussa, R. M., de Jeu, R. A. M., Beck, H. E., Holmes, T. R. H., Jiménez, C., Verhoest, N. E. C., Dorigo, W. A., Teuling, A. J., and Johannes Dolman, A.: El Niño-La Niña cycle and recent trends in continental evaporation, Nat. Clim. Change, 4, 122-126, doi:10.1038/nclimate2068, 2014.

Mu, Q., Heinsch, F. A., Zhao, M., and Running, S. W.: Development of a global evapotranspiration algorithm based on MODIS and global meteorology data, Remote Sens. Environ., 111, 519-536, doi:10.1016/j.rse.2007.04.015, 2007.

Mueller, B., Hirschi, M., Jimenez, C., Ciais, P., Dirmeyer, P. A., Dolman, A. J., Fisher, J. B., Jung, M., Ludwig, F., Maignan, F., Miralles, D. G., McCabe, M. F., Reichstein, M., Sheffield, J., Wang, K., Wood, E. F., Zhang, Y., and Seneviratne, S. I.: Benchmark products for land evapotranspiration: LandFluxEVAL multi-data set synthesis, Hydrol. Earth Syst. Sci., 17, 3707-3720, doi:10.5194/hess-17-3707-2013, 2013.

Oleson, K., Dai, Y., Bonan, G., Bosilovichm, M., Dickinson, R., Dirmeyer, P., Hoffman, F., Houser, P., Levis, S., Niu, G.-Y., Thornton, P., Vertenstein, M., Yang, Z.-L., and Zeng, X.: Technical Description of the Community Land Model (CLM), Tech. Rep. Technical Report NCAR/TN-461+STR, National Center for Atmospheric Research, Boulder, CO 80307-3000, USA, 2004.

Onogi, K., Tsutsui, J., Koide, H., Sakamoto, M., Kobayashi, S., Hatsushika, H., Matsumoto, T., Yamazaki, N., Kamahori, H., Takahashi, K., Kadokura, S., Wada, K., Kato, K., Oyama, R., Ose, T., Mannoji, N., and Taira, R.: The JRA-25 reanalysis, J. Meteorol. Soc. Jpn., 85, 369-432, doi:10.2151/jmsj.85.369, 2007.

Pinker, R. T. and Ewing, J. A.: Modeling surface solar radiation: model formulation and validation, $\mathrm{J}$. Clim. Appl. Meteorol., 24, 389-401, doi:10.1175/15200450(1985)024<0389:MSSRMF>2.0.CO;2, 1985.

Pinker, R. T. and Laszlo, I.: Modeling surface solar irradiance for satellite applications on a global scale,
J. Appl. Meteorol., 31, 194-211, doi:10.1175/1520 0450(1992)031<0194:MSSIFS>2.0.CO;2, 1992.

Pohl, C. and Van Genderen, J. L.: Review article multisensor image fusion in remote sensing: concepts, methods and applications, Int. J. Remote Sens., 19, 823-854, doi:10.1080/014311698215748, 1998.

Qian, Y., Flanner, M. G., Leung, L. R., and Wang, W.: Sensitivity studies on the impacts of Tibetan Plateau snowpack pollution on the Asian hydrological cycle and monsoon climate, Atmos. Chem. Phys., 11, 1929-1948, doi:10.5194/acp-11-19292011, 2011.

Raftery, A. E., Gneiting, T., Balabdaoui, F., and Polakowski, M.: Using Bayesian model averaging to calibrate forecast ensembles, Mon. Weather Rev., 133, 1155-1174, doi:10.1175/mwr2906.1, 2005.

Reichle, R. H., Koster, R. D., De Lannoy, G. J. M., Forman, B. A., Liu, Q., Mahanama, S. P. P., and Touré, A.: Assessment and enhancement of MERRA land surface hydrology estimates, J. Climate, 24, 6322-6338, doi:10.1175/jcli-d-10-05033.1, 2011.

Rienecker, M. M., Suarez, M. J., Gelaro, R., Todling, R., Bacmeister, J., Liu, E., Bosilovich, M. G., Schubert, S. D., Takacs, L., Kim, G.-K., Bloom, S., Chen, J., Collins, D., Conaty, A., da Silva, A., Gu, W., Joiner, J., Koster, R. D., Lucchesi, R., Molod, A., Owens, T., Pawson, S., Pegion, P., Redder, C. R., Reichle, R., Robertson, F. R., Ruddick, A. G., Sienkiewicz, M., and Woollen, J.: MERRA: NASAs Modern-Era Retrospective analysis for Research and Applications, J. Climate, 24, 3624-3648, doi:10.1175/JCLI-D-11-00015.1, 2011.

Robinson, D. A., Dewey, K. F., and Heim, R. R.: Global snow cover monitoring: An update, B. Am. Meteorol. Soc., 74, 1689-1696, doi:10.1175/1520-0477(1993)074<1689:gscmau>2.0.co;2, 1993.

Rodell, M., Houser, P. R., Jambor, U., Gottschalck, J., Mitchell, K., Meng, C. J., Arsenault, K., Cosgrove, B., Radakovich, J., Bosilovich, M., Entin*, J. K., Walker, J. P., Lohmann, D., and Toll, D.: The Global Land Data Assimilation System, B. Am. Meteorol. Soc., 85, 381-394, doi:10.1175/BAMS-85-3-381, 2004.

Rossow, W. B. and Dueñas, E. N.: The International Satellite Cloud Climatology Project (ISCCP) web site: an online resource for research, B. Am. Meteorol. Soc., 85, 167-172, doi:10.1175/BAMS-85-2-167, 2004.

Saha, S., Moorthi, S., Pan, H. L., Behringer, D., Stokes, D., Grumbine, R., Hou, Y. T., Chuang, H. Y., Juang, H. M. H., Sela, J., Iredell, M., Treadon, R., Keyser, D., Derber, J., Ek, M., Lord, S., Van Den Dool, H., Kumar, A., Wang, W., Long, C., Chelliah, M., Xue, Y., Schemm, J. K., Ebisuzaki, W., Xie, P., Higgins, W., Chen, Y., Wu, X., Wang, J., Nadiga, S., Kistler, R., Woollen, J., Liu, H., Gayno, G., Kleist, D., Van Delst, P., Meng, J., Wei, H., Yang, R., Chen, M., Zou, C. Z., Han, Y., Cucurull, L., Goldberg, M., Liu, Q., Rutledge, G., Tripp, P., Reynolds, R. W., Huang, B., Lin, R., and Zhou, S.: The NCEP climate forecast system reanalysis, B. Am. Meteorol. Soc., 91, 1015-1057, doi:10.1175/2010BAMS3001.2, 2010.

Sato, N., Sellers, P. J., Randall, D. A., Schneider, E. K., Shukla, J., Kinter, J. L., Hou, Y. T., and Albertazzi, E.: Effects of implementing the Simple Biosphere Model in a general circulation model, J. Atmos. Sci., 46, 2757-2782, doi:10.1175/15200469(1989)046<2757:eoitsb>2.0.co;2, 1989. 
Sellers, P. J., Mintz, Y., Sud, Y. C., and Dalcher, A.: A Simple Biosphere Model (SIB) for use within general circulation models, J. Atmos. Sci., 43, 505-531, doi:10.1175/15200469(1986)043<0505:asbmfu>2.0.co;2, 1986.

Sellers, P. J., Randall, D. A., Collatz, G. J., Berry, J. A., Field, C. B., Dazlich, D. A., Zhang, C., Collelo, G. D., and Bounoua, L.: A revised land surface parameterization ( $\mathrm{SiB} 2)$ for atmospheric GCMS. Part I: Model formulation, J. Climate, 9, 676-705, doi:10.1175/1520-0442(1996)009<0676: $\operatorname{arlspf>2.0.co;2,~} 1996$.

Shi, Q. and Liang, S.: Characterizing the surface radiation budget over the Tibetan Plateau with ground-measured, reanalysis, and remote sensing data sets: 1 . Methodology, J. Geophys. Res.Atmos., 118, 9642-9657, doi:10.1002/jgrd.50720, 2013a.

Shi, Q. and Liang, S.: Characterizing the surface radiation budget over the Tibetan Plateau with ground-measured, reanalysis, and remote sensing data sets: 2 . Spatiotemporal analysis, J. Geophys. Res.-Atmos., 118, 8921-8934, doi:10.1002/jgrd.50719, 2013b.

Stephens, G. L., Li, J., Wild, M., Clayson, C. A., Loeb, N., Kato, S., L'Ecuyer, T., Stackhouse, P. W., Lebsock, M., and Andrews, T.: An update on Earth's energy balance in light of the latest global observations, Nat. Geosci., 5, 691-696, doi:10.1038/ngeo1580, 2012.

Stevens, B. and Schwartz, S.: Observing and modeling Earth's energy flows, Surv. Geophys., 33, 779-816, doi:10.1007/s10712012-9184-0, 2012.

Stieglitz, M., Ducharne, A., Koster, R., and Suarez, M.: The impact of detailed snow physics on the simulation of snow cover and subsurface thermodynamics at continental scales, J. Hydrometeorol., 2, 228-242, doi:10.1175/15257541(2001)002<0228:tiodsp>2.0.co;2, 2001.

Sugita, M., Nohara, D., Miyazaki, S., Yamanaka, T., Kimura, F., and Yasunari, T.: GAME Asian Automatic Weather Station Network (AAN) Data Set Version 3.0, available at the AAN Data Center at http://www.suiri.tsukuba.ac.jp/Project/aan/aan.html (last access: 8 July 2013) and on GAME CD-ROM No. 13. GAME AAN Working Group Office, Terrestrial Environment Research Center, University of Tsukuba, Tsukuba, Ibaraki, Japan, 2005.

Tanaka, K., Tamagawa, I., Ishikawa, H., Ma, Y., and Hu, Z.: Surface energy budget and closure of the eastern Tibetan Plateau during the GAME-Tibet IOP 1998, J. Hydrol., 283, 169-183, doi:10.1016/s0022-1694(03)00243-9, 2003.

Trenberth, K. E., Fasullo, J. T., and Kiehl, J.: Earth's global energy budget, B. Am. Meteorol. Soc., 90, 311-323, doi:10.1175/2008bams2634.1, 2009.

Tucker, C. J., Pinzon, J. E., Brown, M. E., Slayback, D. A., Pak, E. W., Mahoney, R., Vermote, E. F., and El Saleous, N.: An extended AVHRR 8-km NDVI dataset compatible with MODIS and SPOT vegetation NDVI data, Int. J. Remote Sens., 26, 44854498, doi:10.1080/01431160500168686, 2005.

Turner, A. and Slingo, J.: Using idealized snow forcing to test teleconnections with the Indian summer monsoon in the Hadley Centre GCM, Clim. Dynam., 36, 1717-1735, doi:10.1007/s00382010-0805-3, 2011.

Twine, T. E., Kustas, W. P., Norman, J. M., Cook, D. R., Houser, P. R., Meyers, T. P., Prueger, J. H., Starks, P. J., and Wesely, M. L.: Correcting eddy-covariance flux underestimates over a grassland, Agr. Forest Meteorol., 103, 279-300, doi:10.1016/s01681923(00)00123-4, 2000.
Vapnik, V.: The Nature of Statistical Learning Theory, Information Science and Statistics, Springer, New York, 1999.

Vickers, D. and Mahrt, L.: Quality control and flux sampling problems for tower and aircraft data, J. Atmos. Ocean. Tech., 14, 512-526, doi:10.1175/15200426(1997)014<0512:QCAFSP>2.0.CO;2, 1997.

Vinukollu, R. K., Meynadier, R., Sheffield, J., and Wood, E. F.: Multi-model, multi-sensor estimates of global evapotranspiration: climatology, uncertainties and trends, Hydrol. Process., 25, 3993-4010, doi:10.1002/hyp.8393, 2011.

Viterbo, P. and Beljaars, A. C. M.: An improved land surface parameterization scheme in the ECMWF Model and its validation, J. Climate, 8, 2716-2748, doi:10.1175/15200442(1995)008<2716:ailsps>2.0.co;2, 1995.

Viterbo, P. and Betts, A. K.: Impact on ECMWF forecasts of changes to the albedo of the boreal forests in the presence of snow, J. Geophys. Res.-Atmos., 104, 27803-27810, doi:10.1029/1998jd200076, 1999.

Wang, A. and Zeng, X.: Evaluation of multireanalysis products with in situ observations over the Tibetan Plateau, J. Geophys. Res., 117, D05102, doi:10.1029/2011jd016553, 2012.

Wang, B., Bao, Q., Hoskins, B., Wu, G., and Liu, Y.: Tibetan Plateau warming and precipitation changes in East Asia, Geophys. Res. Lett., 35, L14702, doi:10.1029/2008g1034330, 2008.

Wang, K. and Liang, S.: An improved method for estimating global evapotranspiration based on satellite determination of surface net radiation, vegetation index, temperature, and soil moisture, J. Hydrometeorol., 9, 712-727, doi:10.1175/2007jhm911.1, 2008.

Wang, K. and Dickinson, R. E.: A review of global terrestrial evapotranspiration: observation, modeling, climatology, and climatic variability, Rev. Geophys., 50, RG2005, doi:10.1029/2011RG000373, 2012.

Wang, Y., Xu, X., Lupo, A. R., Li, P., and Yin, Z.: The remote effect of the Tibetan Plateau on downstream flow in early summer, J. Geophys. Res.-Atmos., 116, D19108, doi:10.1029/2011jd015979, 2011.

Webb, E. K., Pearman, G. I., and Leuning, R.: Correction of flux measurements for density effects due to heat and water vapour transfer, Q. J. Roy. Meteor. Soc., 106, 85-100, doi:10.1002/qj.49710644707, 1980.

Wei, C.-C. and Roan, J.: Retrievals for the Rainfall Rate over Land Using Special Sensor Microwave Imager Data during Tropical Cyclones: Comparisons of Scattering Index, Regression, and Support Vector Regression, J. Hydrometeorol., 13, 1567-1578, doi:10.1175/jhm-d-11-0118.1, 2012.

Wild, M.: Enlightening global dimming and brightening, B. Am. Meteorol. Soc., 93, 27-37, doi:10.1175/bams-d-11-00074.1, 2012.

Wu, G., Liu, Y., Zhang, Q., Duan, A., Wang, T., Wan, R., Liu, X., Li, W., Wang, Z., and Liang, X.: The influence of mechanical and thermal forcing by the Tibetan Plateau on Asian climate, J. Hydrometeorol., 8, 770-789, doi:10.1175/JHM609.1, 2007.

Wu, G., Liu, Y., He, B., Bao, Q., Duan, A., and Jin, F.: Thermal controls on the Asian summer monsoon, Sci. Rep., 2, 404, doi:10.1038/srep00404, 2012.

Wu, H., Zhang, X., Liang, S., Yang, H., and Zhou, G.: Estimation of clear-sky land surface longwave radiation from MODIS data products by merging multiple models, J. Geophys. Res.-Atmos., 117, D22107, doi:10.1029/2012jd017567, 2012. 
Xie, P., Yatagai, A., Chen, M., Hayasaka, T., Fukushima, Y., Liu, C., and Yang, S.: A Gauge-based analysis of daily precipitation over East Asia, J. Hydrometeorol., 8, 607-626, doi:10.1175/jhm583.1, 2007.

Xue, B.-L., Wang, L., Li, X., Yang, K., Chen, D., and Sun, L.: Evaluation of evapotranspiration estimates for two river basins on the Tibetan Plateau by a water balance method, J. Hydrol., 492, 290297, doi:10.1016/j.jhydrol.2013.04.005, 2013.

Yanai, M. and Li, C. F.: Mechanism of heating and the boundary layer over the Tibetan Plateau, Mon. Weather Rev., 122, 305323, doi:10.1175/1520-0493(1994)122<0305:mohatb>2.0.co;2, 1994.

Yang, K., Koike, T., Fujii, H., Tamagawa, K., and Hirose, N.: Improvement of surface flux parametrizations with a turbulencerelated length, Q. J. Roy. Meteor. Soc., 128, 2073-2087, doi:10.1256/003590002320603548, 2002.

Yang, K., Koike, T., and Yang, D. W.: Surface flux parameterization in the Tibetan Plateau, Bound.-Lay. Meteorol., 106, 245262, doi:10.1023/a:1021152407334, 2003.

Yang, K., Koike, T., Ishikawa, H., and Ma, Y. M.: Analysis of the surface energy budget at a site of GAME/Tibet using a single-source model, J. Meteorol. Soc. Jpn., 82, 131-153, doi:10.2151/jmsj.82.131, 2004.

Yang, K. and Koike, T.: Satellite monitoring of the surface water and energy budget in the central Tibetan Plateau, Adv. Atmos. Sci., 25, 974-985, doi:10.1007/s00376-008-0974-8, 2008.

Yang, K., Koike, T., Ishikawa, H., Kim, J., Li, X., Liu, H., Liu, S., Ma, Y., and Wang, J.: Turbulent flux transfer over bare-soil surfaces: characteristics and parameterization, J. Appl. Meteorol. Clim., 47, 276-290, doi:10.1175/2007jamc1547.1, 2008.

Yang, K., Qin, J., Guo, X., Zhou, D., and Ma, Y.: Method development for estimating sensible heat flux over the Tibetan Plateau from CMA data, J. Appl. Meteorol. Clim., 48, 2474 2486, doi:10.1175/2009jamc2167.1, 2009.

Yang, K., Guo, X., He, J., Qin, J., and Koike, T.: On the climatology and trend of the atmospheric heat source over the Tibetan Plateau: an experiments-supported revisit, J. Climate, 24, 15251541, doi:10.1175/2010jcli3848.1, 2011a.

Yang, K., Guo, X., and Wu, B.: Recent trends in surface sensible heat flux on the Tibetan Plateau, Sci. China Ser. D., 54, 19-28, doi:10.1007/s11430-010-4036-6, 2011b.

Yang, W., Guo, X., Yao, T., Yang, K., Zhao, L., Li, S., and Zhu, M.: Summertime surface energy budget and ablation modeling in the ablation zone of a maritime Tibetan glacier, J. Geophys. Res., 116, D14116, doi:10.1029/2010jd015183, 2011c.
Yao, J., Zhao, L., Ding, Y., Gu, L., Jiao, K., Qiao, Y., and Wang, Y.: The surface energy budget and evapotranspiration in the Tanggula region on the Tibetan Plateau, Cold Reg. Sci. Technol., 52, 326-340, doi:10.1016/j.coldregions.2007.04.001, 2008.

Yao, J., Zhao, L., Gu, L., Qiao, Y., and Jiao, K.: The surface energy budget in the permafrost region of the Tibetan Plateau, Atmos. Res., 102, 394-407, doi:10.1016/j.atmosres.2011.09.001, 2011.

Yao, Y., Liang, S., Qin, Q., Wang, K., Liu, S., and Zhao, S.: Satellite detection of increases in global land surface evapotranspiration during 1984-2007, Int. J. Digit. Earth, 5, 299-318, doi:10.1080/17538947.2011.598953, 2012.

Ye, D. and Gao, Y.: The meteorology of the Qinghai-Xizang (Tibet) Plateau, Science Press, Beijing, 1979 (in Chinese).

Ye, D. and Wu, G.: The role of the heat source of the Tibetan Plateau in the general circulation, Meteorol. Atmos. Phys., 67, 181-198, doi:10.1007/bf01277509, 1998.

Yu, G. R., Wen, X. F., Sun, X. M., Tanner, B. D., Lee, X., and Chen, J. Y.: Overview of ChinaFLUX and evaluation of its eddy covariance measurement, Agr. Forest Meteorol., 137, 125-137, doi:10.1016/j.agrformet.2006.02.011, 2006.

Zhang, G., Kang, S., Fujita, K., Huintjes, E., Xu, J., Yamazaki, T., Haginoya, S., Wei, Y., Scherer, D., Schneider, C., and Yao, T.: Energy and mass balance of Zhadang glacier surface, central Tibetan Plateau, J. Glaciol., 59, 137-148, doi:10.3189/2013JoG12J152, 2013.

Zhang, K., Kimball, J. S., Mu, Q., Jones, L. A., Goetz, S. J., and Running, S. W.: Satellite based analysis of northern ET trends and associated changes in the regional water balance from 1983 to 2005, J. Hydrol., 379, 92-110, doi:10.1016/j.jhydrol.2009.09.047, 2009.

Zhang, K., Kimball, J. S., Nemani, R. R., and Running, S. W.: A continuous satellite-derived global record of land surface evapotranspiration from 1983 to 2006, Water Resour. Res., 46, W09522, doi:10.1029/2009wr008800, 2010.

Zhu, X., Liu, Y., and Wu, G.: An assessment of summer sensible heat flux on the Tibetan Plateau from eight data sets, Sci. China Ser. D., 55, 779-786, doi:10.1007/s11430-012-4379-2, 2012.

Zou, H.: The adaptive lasso and its oracle properties, J. Am. Stat. Assoc., 101, 1418-1429, doi:10.1198/016214506000000735, 2006.

Zou, H., Ma, S., Zhou, L., Li, P., and Li, A.: Measured turbulent heat transfer on the northern slope of Mt. Everest and its relation to the south Asian summer monsoon, Geophys. Res. Lett., 36, L09810, doi:10.1029/2008g1036984, 2009. 